Elsevier required licence: (c) $<2016\rangle$. This manuscript version is made available under the CC-BY-NC-ND 4.0 license http://creativecommons.org/licenses/bync-nd/4.0/ 


\title{
Leveraged investments and agency conflicts when cash flows are mean reverting
}

\author{
Kristoffer J. Glovera, ${ }^{\mathrm{a}, \mathrm{w}}$, Gerhard Hambusch ${ }^{\mathrm{a}, \mathrm{b}, \mathrm{c}}$ \\ ${ }^{a}$ Finance Discipline Group, UTS Business School, University of Technology Sydney, Broadway NSW 2007, Australia \\ ${ }^{b}$ Quantitative Finance Research Centre, University of Technology, Sydney, Broadway NSW 2007, Australia \\ ${ }^{c}$ Centre for Applied Macroeconomic Analysis, Australian National University, Canberra ACT 0200, Australia
}

\begin{abstract}
We analyse the effect of mean-reverting cash flows on the costs of shareholder-bondholder conflicts arising from partially debt-financed investments. In a partial equilibrium setting we find that such agency costs are significantly lower under mean-reverting (MR) dynamics, when compared to the ubiquitous geometric Brownian motion (GBM). The difference is attributed to the stationarity of the MR process. In addition, through the application of a novel agency cost decomposition, we show that for a larger speed of mean reversion, agency costs are driven mainly by suboptimal timing decisions, as opposed to suboptimal financing decisions. In contrast, under the standard GBM assumption the agency costs are driven mainly by suboptimal financing decisions for large growth rates and by suboptimal timing decisions for smaller or negative growth rates.
\end{abstract}

Keywords: investment, real option, mean reversion, agency conflicts

JEL classification: G13, G32, G33, G38.

\section{Introduction}

The bulk of the existing real options literature assumes uncertain output or input prices to follow geometric Brownian motion (GBM) (Dixit and Pindyck, 1994). While this modelling choice often provides tractable solutions it has been criticised in relation to its suitability for describing equilibrium price processes (Lund, 1993). It has also been suggested that such price dynamics, particularly in commodity markets, can be more accurately modelled using a mean-reverting (MR) process (Schwartz, 1997). Crucially, it has also been argued that the failure to account for the effects of mean reversion can lead to "systematic biases in capital budgeting decisions" (Bessembinder, Coughenour, Seguin, and Smoller, 1995).

Motivated by the above, an important line of research, initiated by Metcalf and Hassett (1995), has attempted to assess the appropriateness of using GBM as a substitute for more realistic meanreverting dynamics when considering firms' optimal investment decisions. The present paper continues this line of research by considering the effect of mean reversion on leveraged investment

\footnotetext{
${ }^{*}$ Corresponding author. Tel.: +61-2 9514 7778; fax: +61-2 95147711.

Email address: kristoffer.glover@uts. edu. au (Kristoffer J. Glover)
} 
projects. Considering leverage extends the previous analysis to a more realistic and economically meaningful setting, however it requires the explicit consideration of the shareholders' default option and the rational response of the debt providers to this default; thus introducing strategic interaction into the model. Because of this, the effect of MR on optimal investment in this setting is, unsurprisingly, more complex.

However, the inclusion of leverage into this framework allows us to evaluate the additional effects of mean reversion on the optimal financing decisions of firms and to investigate the interaction of the financing and investment timing decisions. ${ }^{1}$ To our knowledge the effect of mean reversion on this interaction has not previously been studied. This research therefore contributes to the literature on real options and stochastic price modelling as well as to the literature on corporate financial policy and related agency conflicts.

To date, three effects of mean reversion on investments (when compared to GBM) have been identified. Metcalf and Hassett (1995) expounded the variance effect in which mean reversion reduces the long-run variance of a project's cash flow, resulting in a lower investment price threshold. However, these authors also noted a second, competing, realised price effect, in which the stationarity of the mean-reverting process implies that the probability of reaching a given level is also reduced. This additional effect could potentially offset the variance effect and subsequently Metcalf and Hassett (1995) concluded that GBM could be considered as an appropriate substitute for MR since the probability of investment under GBM and MR dynamics are comparable, resulting in no significant difference in cumulative investment. Sarkar (2003) extended Metcalf and Hassett's arguments by incorporating a third risk-discounting effect. Under mean reversion, a lower cash-flow variance also affects the project's risk-adjusted required rate of return and hence the discount rate used for valuation; affecting both the project value and the value of the real option to invest in the project. In contrast to Metcalf and Hassett (1995), Sarkar (2003) concluded that mean reversion does have a significant impact on investment when all three effects are correctly accounted for.

In two recent contributions to this literature, Tsekrekos examined the effect of mean reversion on irreversible exit decisions of firms (Tsekrekos, 2013) and on reversible entry and exit decisions of firms (Tsekrekos, 2010); thus incorporating the possibility of reversibility and disinvestment into the analysis. Similar to Sarkar (2003), Tsekrekos $(2010,2013)$ also reached the conclusion that it would be erroneous to use the more tractable GBM process as an approximation for a meanreverting process in models of aggregate industry investment and disinvestment. We note that neither Tsekrekos $(2010,2013)$, nor the previous papers, considered a setting in which leverage was present.

Leverage introduces the potential for conflicting interests of shareholders (borrowers) and bondholders (lenders). ${ }^{2}$ This introduces agency costs as a fundamental quantity in our investment and financing problem (Jensen and Meckling, 1976). ${ }^{3}$ Existing literature has analysed the

\footnotetext{
${ }^{1}$ Since Modigliani and Miller's ground-breaking work on optimal capital structure (Modigliani and Miller, 1959, Baxter, 1967) investment valuation has been closely linked to questions of optimal corporate financial policy. Financial structure is important for the valuation itself because it influences the policy that governs cash flow control, which in turn affects cash flows and the project value (Brennan and Trigeorgis, 2000).

${ }^{2}$ In the following, we use the terms equityholders and debtholders to maintain generality.

${ }^{3}$ The investment decision-makers (managers) are assumed to be the shareholders and hence agency conflicts are
} 
direction and magnitude of the agency costs resulting from over- or underinvestment. When new projects are financed solely by equity, some researchers have concluded that equityholders tend to underinvest, because they bear all the cost of the investment while sharing the benefits with debtholders (Mauer and Ott, 2000, Moyen, 2007, Titman and Tsyplakov, 2007). In contrast to this, when projects are at least partially financed by new debt, equityholders tend to overinvest due to the incentive to transfer wealth from the debtholders to themselves (Leland, 1998, Mauer and Sarkar, 2005). ${ }^{4}$

In the context of leveraged investments, the model of Mauer and Sarkar (2005) is particularly appealing as it presents agency conflicts using a two-layered real option framework; the project investment option and the default option after investment. This setup allows the rational debtholders to incorporate the equityholders' strategy of equity-value maximisation when deciding on how much debt to provide and at what price. Therefore, in light of the significance of the effects of mean reversion on investment timing decisions, we extend the (GBM based) model of Mauer and Sarkar (2005) to a more general analysis, incorporating the risk-discounting effect of Sarkar (2003), and allowing for the consideration of mean-reverting dynamics; thus providing insights into their effects on both investment and financing decisions.

The GBM based results of Mauer and Sarkar (2005) find that equityholders' incentive to overinvest significantly decreases firm value and optimal leverage, reporting a $9.4 \%$ loss in firm value and a reduction in optimal leverage from $66 \%$ to $39 \%$ for their base-case parameters. Our analysis reveals similar results under GBM-8.5\% loss in firm value and a reduction in leverage from $60 \%$ to $45 \%$ - but that under mean-reverting dynamics the reductions in firm value and optimal leverage are much smaller, finding only a $1.0 \%$ loss in firm value and a reduction of optimal leverage from $48 \%$ to $44 \%$ for our base-case parameters. These results indicate that the growth rate and stationarity assumptions of future cash-flow expectations have a significant impact on the equilibrium effects of the agency conflict.

In sum, this research extends the current literature in the following ways. Firstly, we generalise the model of Mauer and Sarkar (2005) to a wider class of diffusion processes and incorporate the risk-discounting effect as proposed by Sarkar (2003). Secondly, when considering the agency costs of overinvestment, we propose a novel agency cost decomposition into the costs due to suboptimal financing decisions and those due to suboptimal (default and investment) timing decisions. Finally, we also parameterise our model using real (commodity) asset price data to provide a concrete example of our findings.

The remainder of the paper is structured as follows. Our model is developed and solved under a general MR uncertainty process in Section 2, results are provided and discussed in Section 3, and conclusions drawn in Section 4. The more technical details are presented in the appendices.

\footnotetext{
between shareholders and bondholders. If the decision makers are not shareholders, there could be additional conflicts of interests between shareholders and managers (cf. Cadenillas, Cvitanic, and Zapatero, 2004, Morellec, 2004).

${ }^{4}$ Note that, like Mauer and Sarkar (2005), this paper considers the agency cost of overinvestment since we have partially debt financed investments and the assumption of no existing debt prior to investment.
} 


\section{A mean-reverting model}

In the following we develop an extension of the Mauer and Sarkar (2005) model under MR dynamics. ${ }^{5}$ In the model, equityholders have the option to invest in a project at any time and further to finance the cost of the project with a level of debt of their choosing. After investment, the equityholders have the subsequent option to abandon the project and default on any existing debt.

The investment project is assumed to yield a mean-reverting profit (EBIT) equal to $X_{t}-C$. This could represent, for example, the per unit profit of producing a mean-reverting commoditysold at the uncertain price $\left(X_{t}\right)_{t \geq 0}$-at a constant cost $C$. Alternatively, we could interpret $X$ as the variable contribution margin (i.e., revenue minus variable costs) of a project in a more general industry. With this interpretation, we need not restrict ourselves to the commodity industry and our results would hold for any firm facing mean-reverting earnings. Indeed, we note that Bhattacharya (1978) provided some theoretical rationale for mean-reverting earnings and many empirical studies have revealed a tendency of corporate earnings to mean revert (see, for example, Freeman, Ohlson, and Penman, 1982, Kormendi and Lipe, 1987, Raymar, 1991, Fama and French, 2000, Sarkar and Zapatero, 2003). To remain consistent with Mauer and Sarkar (2005), however, we retain their uncertain output price formulation in the following. ${ }^{6}$

The per period profits $X_{t}-C$ are taxed at the constant effective tax rate $\tau$. The project is subject to initial investment costs $I$ and both the underlying project and the option to invest are assumed to have infinite time-horizons. Financing of the project is assumed to be undertaken by a mixture of both equity and perpetual debt, where the latter is denoted $K$. In exchange for the financing amount $K$, equityholders are required to pay a periodic coupon payment $R$. The debt amount $K$ and coupon payment $R$ are pre-negotiated from a 'revolving line of credit' type of loan commitment, which equity- and debtholders have agreed upon at $t=0$, before the investment decision is taken. ${ }^{7}$ Debtholders are assumed to be rational and set the equityholders' coupon payment $R$ not only based on the level of debt provided $K$, but also on their expectation of the equityholders' behaviour regarding default and investment. In the case of default the equity value is assumed to be zero and the bankruptcy costs amount to a fraction $b$ of the value of the unlevered project at time of default, with debtholders receiving the remainder.

Since optimal timing decisions are usually determined using backward induction we begin by modelling the inner option, representing the value of the project after investment. Given the investor's ability to abandon the project the valuation of the inner option requires determining the optimal abandonment strategy. In the case of the levered project, such abandonment is labelled as default. Next, we evaluate the outer option, which represents the value of the investment project to the investor before investment. This option must account for uncertain future output prices, the investor's optimal timing decisions, and the lender's optimal decision on providing debt. As such,

\footnotetext{
${ }^{5}$ The model can be generalized to a fairly large class of time-homogeneous diffusions which encompasses many well known processes used in modern finance, such as the GBM, CIR and CEV models (see Black and Scholes, 1973, Cox, Ingersoll, and Ross, 1985, Cox, 1975, respectively). More details are available from the authors upon request.

${ }^{6}$ The interested reader may refer to Glover and Hambusch (2014) where the alternative interpretation is made.

${ }^{7}$ This type of commitment allows the equityholders to borrow, on pre-negotiated terms, at any time during the life of the commitment. For more details see Kashyap, Rajan, and Stein (2002).
} 
a strategic equilibrium (under complete information) between investor (equityholders) and lender (debtholders) is determined.

\subsection{Uncertainty assumption}

To incorporate mean reversion into the price dynamics we model the price process $\left(X_{t}\right)_{t \geq 0}$ as the following arithmetic mean-reverting (AMR) process living on the filtered probability space $\left(\Omega, \mathrm{P},\left\{\mathcal{F}_{t}\right\}_{t \geq 0}, \mathcal{F}\right)$ :

$$
d X_{t}=\eta\left(\bar{x}-X_{t}\right) d t+\sigma X_{t} d W_{t}, \quad X_{0}=x,
$$

where $d W_{t}$ denotes the increment of a Wiener process under the measure $\mathrm{P}, \sigma(>0)$ denotes the volatility of the process, and $\eta$ the speed of mean reversion which determines the rate at which $X$ returns to $\bar{x}(\geq 0)$, the expected long-run price level. The parameter $\eta$ is assumed to be nonnegative except in the scenario when $\bar{x}=0$, in which case $\eta$ can take any real value. The process (1) is known as inhomogeneous geometric Brownian motion (IGBM) $)^{8}$ due to the inhomogeneity of its expected return in the state variable $X$. In comparison to Mauer and Sarkar (2005) the process in Eq. (1) is a stationary process as opposed to the non-stationary GBM process employed by those and many other authors.

The use of the process (1) in real option analysis dates back to Bhattacharya (1978) and has been applied more recently by Insley (2002), Abadie and Chamorro (2008), Hong and Sarkar (2008) and Tsekrekos $(2010,2013)$ amongst others. Whilst this process is only one of many potential mean-reverting processes that could be used, our reasons for choosing this particular process are manyfold. First, like GBM, the IGBM mean-reverting model guarantees positive process values. Second, Zhao (2009) showed that IGBM has many appealing closed-form properties despite not being of the more tractable affine class. Thirdly, and perhaps most importantly, it can be seen that geometric Brownian motion (GBM) can be obtained as a special case of IGBM by setting $\eta=0$ (for driftless GBM) or $\bar{x}=0$ and $\eta=-\alpha$, where $\alpha$ denotes the drift of the resulting GBM dynamics. This reduction allows for a direct comparison of both the IGBM and GBM processes. Finally, the IGBM process was also employed by Sarkar (2003) and Tsekrekos (2010, 2013) and so our results can be directly compared to these important papers.

\subsection{Valuation principle}

The project and firm valuations derived in this paper are done so via equilibrium arguments similar to those found in Bhattacharya (1978), Sarkar (2003) and Tsekrekos (2010), amongst other. ${ }^{9}$ To explicitly take into account the risk-discounting effect, outlined by Sarkar (2003), we appeal to the intertemporal capital asset pricing model (CAPM) of Merton (1973), which incorporates the relationship between systematic risk and the discount rate used for valuation. Inclusion

\footnotetext{
${ }^{8}$ In the existing literature, this process has been called, amongst other things, 'inhomogeneous geometric Brownian motion' (IGBM) (see Abadie and Chamorro, 2008, Zhao, 2009), 'Geometric Ornstein-Uhlenbeck' (GOU) (see Insley, 2002) or 'geometric Brownian motion with affine drift' (see Linetsky, 2004). To be consistent with the more recent literature we refer to this process as IGBM.

${ }^{9}$ Alternatively, if an argument could be made for market completeness, risk-neutral valuation could be employed; see, for example, Duffie (1998), Section 17 or Huang and Litzenberger (1990), Chapter 8. However, since the underlying project cash-flows may not be tradable or fully replicable in the market, we choose to employ a more general equilibrium valuation approach.
} 
of this feature is important in the present setting since mean reversion reduces systematic risk and hence the discount rate used for valuation should not be treated as a constant across different process assumptions. The use of CAPM is a convenient mechanism in which to incorporate this intuition and is consistent with the papers upon which our research builds.

\subsection{Unlevered project value}

To start, we consider the inner option determining the unlevered project value after investment. We denote by $V_{u}$ the equilibrium value of the unlevered project and furthermore we assume that the project manager will act optimally in exercising their option to abandon the project should output prices (earnings) become too low. Given the project's assumed infinite horizon, its value will not depend on calender time $t$ and the optimal abandonment policy will be to abandon the project the first time the process $X$ reaches a constant level $x_{a}^{*}$ (to be determined). Hence, the project will continue to operate provided the process $X$ remains in the interval $\left(x_{a}^{*}, \infty\right)$. In this interval we can exploit Itô's formula and the intertemporal CAPM to determine the differential equation that $V_{u}$ must satisfy. To do so, we note that the total return on an investment in the unlevered project (denoted $R_{u}$ ) is derived from two sources: (1) the expected capital gain $\mathbb{E}\left[d V_{u}\right] / d t$, and (2) the cash inflow per unit time $\pi_{u}$, defined as

$$
\pi_{u}(x)=(1-\tau)(x-C)
$$

i.e. the after-tax profit of the project. Applying Itô's formula we thus observe that the expected return and standard deviation of return of the active project are given by

$$
\begin{aligned}
\mathbb{E}\left[R_{u} \mid X_{t}=x\right] & =\lim _{d t \downarrow 0} \frac{\left(\mathbb{E}\left[d V_{u}\left(X_{t+d t}\right)+\pi_{u}\left(X_{t+d t}\right) d t \mid X_{t}=x\right]\right) / d t}{V_{u}(x)} \\
& =\frac{\frac{1}{2} \sigma^{2} x^{2} V_{u}^{\prime \prime}(x)+\eta(\bar{x}-x) V_{u}^{\prime}(x)+\pi_{u}(x)}{V_{u}(x)}, \\
\sigma\left(R_{u} \mid X_{t}=x\right) & =\frac{\sigma x V_{u}^{\prime}(x)}{V_{u}(x)},
\end{aligned}
$$

where primes denote derivatives. Next, from the continuous-time CAPM of Merton (1973), we require that the relationship between risk and return satisfies

$$
\mathbb{E}\left[R_{u}\right]=r+\lambda \rho \sigma\left(R_{u}\right),
$$

where $r$ denotes the risk-free rate of return, $\rho$ the correlation of changes in $X$ with the return of the market portfolio, $R_{m}$, and $\lambda=\left(\mathbb{E}\left[R_{m}\right]-r\right) / \sigma\left(R_{m}\right)$ represents the market price of risk; with $\mathbb{E}\left[R_{m}\right]$ and $\sigma\left(R_{m}\right)$ denoting the expected value and standard deviation, respectively, of the return on the market portfolio. We assume that both the market price of risk $\lambda$ and the correlation $\rho$ remain constant. Substitution of Eqs. (3) and (4) into Eq. (5) thus results in the following ordinary differential equation (ODE):

$$
\frac{1}{2} \sigma^{2} x^{2} V_{u}^{\prime \prime}(x)+(\eta(\bar{x}-x)-\lambda \rho \sigma x) V_{u}^{\prime}(x)-r V_{u}(x)+\pi_{u}(x)=0 .
$$


This ODE must be solved subject to the following boundary conditions:

$$
\begin{aligned}
& V_{u}\left(x_{a}^{*}\right)=0, \\
& \left.V_{u}^{\prime}(x)\right|_{x=x_{a}^{*}}=0, \\
& \lim _{x \uparrow \infty} V_{u}(x)=f_{u}(x),
\end{aligned}
$$

where $f_{u}$ is to be defined shortly. Condition (7) ensures that the valuation of the unlevered project is zero upon abandonment (at $x=x_{a}^{*}$ ). Condition (8) is the so-called smooth-pasting condition (Dixit and Pindyck, 1994) that ensures optimality of the abandonment threshold $x_{a}^{*}$-being that which maximises the project value over all possible abandonment thresholds. The final condition (9) implies that for extremely high profit levels (i.e., high $x$ ) the likelihood of abandonment is negligible and hence the project valuation would correspond to the valuation of a project that was operated in perpetuity (from an initial value of $x$ ). We denote such a value by $f_{u}$ and note that an expression for its value can be derived from the arguments of Bhattacharya (1978), yielding ${ }^{10}$

$$
f_{u}(x)=(1-\tau)\left(\frac{x}{r+\eta+\lambda \rho \sigma}+\frac{\eta \bar{x}}{r(r+\eta+\lambda \rho \sigma)}-\frac{C}{r}\right)
$$

Interestingly, it can be seen (via direct substitution) that $f_{u}$ is also a particular solution to the ODE in (6). Therefore, the general theory of linear second order differential equations (Coddington and Levinson, 1955) allows us to express the general solution to (6) as

$$
V_{u}(x)=f_{u}(x)+A \phi(x)+B \psi(x)
$$

where $A$ and $B$ are constants to be determined and $\phi$ and $\psi$ denote the two positive independent solutions (decreasing and increasing, respectively) of the associated second-order homogeneous ODE

$$
\frac{1}{2} \sigma^{2} x^{2} u^{\prime \prime}(x)+(\eta(\bar{x}-x)-\lambda \rho \sigma x) u^{\prime}(x)-r u(x)=0
$$

These solutions are found to be

$$
\begin{aligned}
& \phi(x)=x^{\gamma} M\left(-\gamma, 2(1-\gamma)+\frac{2(\eta+\lambda \rho \sigma)}{\sigma^{2}} ; \frac{a}{x}\right), \\
& \psi(x)=x^{\gamma} U\left(-\gamma, 2(1-\gamma)+\frac{2(\eta+\lambda \rho \sigma)}{\sigma^{2}} ; \frac{a}{x}\right)
\end{aligned}
$$

where $M$ and $U$ are confluent hypergeometric functions, $a:=2 \eta \bar{x} / \sigma^{2}$, and $\gamma$ is the negative root of the quadratic $\frac{1}{2} \sigma^{2} \gamma(\gamma-1)-(\eta+\lambda \rho \sigma) \gamma-r=0$. The solution methodology relies on the reduction

\footnotetext{
${ }^{10}$ Identifying $A=\eta, B=\eta \bar{x}, a=\lambda \rho$, and $V=\sigma$ in Eq. (14) of Bhattacharya (1978), we can see that the transformation $V_{u}=(1-\tau)(F-C / r)$ establishes the link between $F$ in (14) and $V_{u}$ in Eq. (6) above. Setting the maturity in Eq. (15) of Bhattacharya (1978) to be infinite thus yields the required result (after a little rearranging).
} 
of Eq. (12) to the standard form of the so-called Kummer's equation. ${ }^{11}$

Applying boundary condition (9) we must conclude that $B=0$ (since $\psi$ is unbounded in this limit) and application of boundary condition (7) reveals that $A=-f_{u}\left(x_{a}^{*}\right) / \phi\left(x_{a}^{*}\right)$. Hence the unlevered firm value can be expressed as

$$
V_{u}(x)= \begin{cases}f_{u}(x)-f_{u}\left(x_{a}^{*}\right) \frac{\phi(x)}{\phi\left(x_{a}^{*}\right)}, & \text { for } x \geq x_{a}^{*}, \\ 0, & \text { for } x<x_{a}^{*},\end{cases}
$$

where the optimal abandonment threshold $x_{a}^{*}$ solves

$$
\frac{\phi^{\prime}\left(x_{a}^{*}\right)}{\phi\left(x_{a}^{*}\right)}=\frac{f_{u}^{\prime}\left(x_{a}^{*}\right)}{f_{u}\left(x_{a}^{*}\right)}
$$

which is obtained from application of the final, smooth-pasting, boundary condition (8). Note that Eq. (16) does not allow us to solve for $x_{a}^{*}$ analytically, however $x_{a}^{*}$ can be found numerically very easily using standard root-finding algorithms. From Eq. (15) we observe that the valuation of the unlevered project can be decomposed into the value of a project that is never abandoned, $f_{u}(x)$, and the value of the 'option' to abandon the project, $-f_{u}\left(x_{a}^{*}\right) \phi(x) / \phi\left(x_{a}^{*}\right){ }^{12}$

Remark 1. Setting $\bar{x} \rightarrow 0$ (and $\eta \rightarrow-\alpha$ ) in Eq. (13) the well known expression for GBM dynamics, $x^{\gamma}$, can be recovered. This can be seen clearly by noting that $\lim _{a \rightarrow 0} M(\cdot, \cdot ; a / x)=1$. We also note that in this limiting case, Eq. (16) can be solved explicitly to yield

$$
x_{a}^{*}=\frac{\gamma C(\alpha-r-\lambda \rho \sigma)}{r(1-\gamma)}
$$

which is consistent with the results of Mauer and Sarkar (2005).

\subsection{Levered project value}

Next, we consider the availability of debt financing, where interest payments are assumed to be tax deductible. Due to the resulting tax-shield, equityholders have the incentive to take on debt to increase the total equity value of the investment. In the presence of coupon payments $R \geq 0$, the profit function of the levered project changes Eq. (2) to

$$
\pi_{\ell}(x)=(1-\tau)(x-C-R) .
$$

Furthermore, the levered project value $V_{\ell}(x)$ after investment is defined as simply the sum of the values of equity and debt

$$
V_{\ell}(x):=E(x)+D(x) .
$$

To determine the equity value of the levered project, $E(x)$, analogous arguments to those outlined above for the unlevered project can be made, but with the cash-flow stream $\pi_{u}$ replaced by $\pi_{\ell}$; i.e.

\footnotetext{
${ }^{11}$ For further details see Appendix A. Ewald and Wang (2010) also provide detail of the solution methodology in the context of a similar real option problem under a similar, CIR-type, mean-reverting process.

${ }^{12}$ Despite the negative sign this option value is indeed positive, since the project manager would only abandon when $f_{u}(x)<0$, i.e. when the associated no-abandonment project had a negative value at the current profit level.
} 
with the fixed operating costs $C$ replaced by the sum of the operating and financing costs, $C+R$. Recall that in the case of the levered project, we term the abandonment of the project as default. Furthermore, the optimal default policy of the equityholders will be the first hitting time of the optimal default threshold $x_{d}^{*}$ (analogous to $x_{a}^{*}$ ). Hence the equity value is found to be ${ }^{13}$

$$
E(x)= \begin{cases}f_{\ell}(x)-f_{\ell}\left(x_{d}^{*}\right) \frac{\phi(x)}{\phi\left(x_{d}^{*}\right)}, & \text { for } x \geq x_{d}^{*}, \\ 0, & \text { for } x<x_{d}^{*}\end{cases}
$$

where

$$
f_{\ell}(x)=f_{u}(x)-\frac{R(1-\tau)}{r},
$$

and $x_{d}^{*}$ solves the equation

$$
\frac{\phi^{\prime}\left(x_{d}^{*}\right)}{\phi\left(x_{d}^{*}\right)}=\frac{f_{\ell}^{\prime}\left(x_{d}^{*}\right)}{f_{\ell}\left(x_{d}^{*}\right)} .
$$

Remark 2. Given the additional cash-flow burden of the amount $R$, it is expected that rational equityholders abandon the project sooner (at a higher output price) due to the lower overall cash inflows. Indeed, it can be shown that $x_{d}^{*} \geq x_{a}^{*}$, for all $R \geq 0 .{ }^{14}$

Remark 3. Noting that equityholders would only default on the project when $f_{\ell}<0$, if parameters were such that $f_{\ell}(x) \geq 0, \forall x \geq 0$, the optimal default trigger price $x_{d}^{*}$ would not exist (since the left-hand-side of Eq. (22) is negative and the right-hand-side would always be positive). Hence it would never be optimal to default on the levered project. Inspection of Eq. (21) reveals that no default is indeed optimal when

$$
\bar{x}-(C+R)>\frac{r+\lambda \rho \sigma}{\eta}(C+R)
$$

i.e. when the project's long-run profit margin is sufficiently large. Furthermore, if Eq. (23) is satisfied, the equity value $E(x)$ remains finite and is given simply by $f_{\ell}(x) .{ }^{15}$ Finally, setting $\bar{x}=0$ and $\eta=-\alpha$, condition (23) can be used to conclude that under geometric Brownian motion with drift $\alpha$, it is never optimal to default (for $C+R>0$ ) if $\alpha \geq r+\lambda \rho \sigma$. However, in this case $(\alpha \geq r+\lambda \rho \sigma)$, the equity value becomes infinite.

The above observations demonstrate clear qualitative differences in investors' behaviour between the GBM and IGBM case. Under the assumption of a GBM uncertainty process the condition $\alpha<r+\lambda \rho \sigma$ is required to ensure that the equity value is finite and investors will always optimally default on the project if subjected to positive costs. Otherwise, if $\alpha \geq r+\lambda \rho \sigma$, equity has an infinite value and trivially the project should never be stopped. ${ }^{16}$ This condition effectively

\footnotetext{
${ }^{13}$ Details are identical to those in Section 2.3 and are therefore omitted in the interests of brevity.

${ }^{14}$ Details are available from the authors upon request.

${ }^{15}$ The same intuition also holds for the optimal abandonment trigger price $x_{a}^{*}$ and the value of the unlevered project $V_{u}(x)$ when $R=0$.

${ }^{16}$ This condition is reminiscent of the popular (Gordon) constant growth model for equity valuation (see Gordon, 1959) in which equity cannot be valued if the expected future growth rate of dividends exceeds the risk-adjusted required rate of return.
} 
restricts the region of applicability of the GBM model. Under the assumption of mean-reversion on the other hand, the equity value $E(x)$ can be seen to remain finite for all parameter regimes, even when it is optimal to never default on the project.

Next, to value the debt, $D(x)$, we observe that the debtholders' periodic cash flow is equal to the coupon payment $R$, provided that the equityholders do not default. In the case of default, debtholders receive the value of the unlevered project less bankruptcy costs. Therefore, applying similar valuation arguments to those outlined above, we observe that the debt value must satisfy the following ODE

$$
\frac{1}{2} \sigma^{2} x^{2} D^{\prime \prime}(x)+(\eta(\bar{x}-x)-\lambda \rho \sigma x) D^{\prime}(x)-r D(x)+R=0
$$

subject to the boundary conditions

$$
\begin{aligned}
& D\left(x_{d}^{*}\right)=(1-b) V_{u}\left(x_{d}^{*}\right), \\
& \lim _{x \uparrow \infty} D(x)=R / r,
\end{aligned}
$$

where we recall that $x_{d}^{*}$ denotes the equityholders' optimal default threshold and $b$ the fractional bankruptcy cost. Note that there is no longer a third optimality (smooth-pasting) condition required for this ODE since debtholders do not have any direct influence on the time of default. The condition in (25) specifies the residual value (net of bankruptcy costs) to be transferred to the debtbholders after the equityholder's default. The condition in (26) implies that for extremely high profit levels (i.e., high $x$ ) the likelihood of abandonment is negligible and hence the debt value corresponds to the valuation of a simple perpetuity with a constant payment of $R$ per time period. In addition, since this cash-flow is risk free, the appropriate discount rate for valuation is simply the risk-free rate $r$, yielding a debt value of $R / r$.

Once more the limiting value $R / r$ turns out to be a particular solution of (24) and application of conditions (25) and (26) to the general solution of (24) yields

$$
D(x)= \begin{cases}\frac{R}{r}+\left((1-b) V_{u}\left(x_{d}^{*}\right)-\frac{R}{r}\right) \frac{\phi(x)}{\phi\left(x_{d}^{*}\right)}, & \text { for } x \geq x_{d}^{*}, \\ (1-b) V_{u}(x), & \text { for } x<x_{d}^{*}\end{cases}
$$

Next, substitution of Eqs. (20) and (27) into Eq. (19) and judicious rearranging provides the following, particularly insightful, representation of the value of the levered project (for $\left.x \geq x_{d}^{*}\right)^{17}$

$$
V_{\ell}(x)=V_{u}(x)+\frac{\tau R}{r}\left(1-\frac{\phi(x)}{\phi\left(x_{d}^{*}\right)}\right)-b V_{u}\left(x_{d}^{*}\right) \frac{\phi(x)}{\phi\left(x_{d}^{*}\right)} .
$$

In other words, the value of the levered project can be expressed as the sum of three components: the value of the unlevered project, the expected additional benefit provided by debt in the form of a tax shield, and the expected cost of bankruptcy. This representation forms the basis for the trade-off theory of optimal capital structure (Kraus and Litzenberger, 1973).

\footnotetext{
${ }^{17}$ See Appendix B for the derivation of Eq. (28). Note that for $x<x_{d}^{*}$, we have $V_{\ell}(x)=D(x)=(1-b) V_{u}(x)$.
} 


\subsection{Second-best investment policy}

The outer option to invest in the project, or firm value, is considered next. ${ }^{18}$ We begin with the case of the second-best investment policy based on the equityholders' desire to maximise equity/shareholder value (as opposed to a first-best policy maximising total firm value). This policy provides the optimal time to undertake the investment from the equityholders' point of view.

In order to value the second-best option to invest we once again appeal to equilibrium arguments and recognize that the investment opportunity held by the firm is analogous to a perpetual American call option-with the payoff at exercise being equal the equity value of the levered project net of the total investment cost to the equityholders (i.e., $I-K$ ). We assume that the equityholders optimally exercise this option, which would occur when the cash flows $(X)$ are high enough. Again, since it is a perpetual option, its value will be independent of calendar time and the optimal investment policy will be to invest in the levered project the first time the process $X$ reaches a constant level $x_{2}^{*}$ (to be determined). Letting the second-best firm value be denoted by $F_{2}(x)$ we observe that this value must satisfy the ODE

$$
\frac{1}{2} \sigma^{2} x^{2} F_{2}^{\prime \prime}(x)+(\eta(\bar{x}-x)-\lambda \rho \sigma x) F_{2}^{\prime}(x)-r F_{2}(x)=0,
$$

subject to the boundary conditions

$$
\begin{aligned}
& F_{2}\left(x_{2}^{*}\right)=E\left(x_{2}^{*}\right)-(I-K), \\
& \left.F_{2}^{\prime}(x)\right|_{x=x_{2}^{*}}=\left.E^{\prime}(x)\right|_{x=x_{2}^{*}}, \\
& \lim _{x \downarrow 0} F_{2}(x)<\infty .
\end{aligned}
$$

Condition (30) indicates that the second-best firm value upon investment is simply the equity value of the levered project in excess of the net investment cost to the equityholders. Condition (31) is another smooth-pasting condition that ensures optimality of the investment threshold $x_{2}^{*}$ - being that which maximises the second-best firm value over all possible investment thresholds. Finally, Eq. (32) ensures that the firm value remains finite as $x$ approaches zero. ${ }^{19}$ Noting that Eq. (29) is homogeneous, and hence requires no particular solution, application of the boundary conditions (30), (31) and (32) to the general solution of (29) yields the following representation of the secondbest firm value:

$$
F_{2}(x)= \begin{cases}\left(E\left(x_{2}^{*}\right)-(I-K)\right) \frac{\psi(x)}{\psi\left(x_{2}^{*}\right)}, & \text { for } x<x_{2}^{*}, \\ E(x)-(I-K), & \text { for } x \geq x_{2}^{*}\end{cases}
$$

\footnotetext{
${ }^{18}$ Note that, like Mauer and Sarkar (2005), we assume the firm undertaking this investment decision has no other existing operations or debt. Hence the investment option value is equivalent to the pure firm value, since there are no additional operations from which to derive value.

${ }^{19}$ Since zero is an entrance-not-exit boundary point for the IGBM process (see Karlin and Taylor, 1999) the usual zero-value condition, $\lim _{x \downarrow 0} F_{2}(x)=0$ (which is appropriate under GBM dynamics) cannot be applied here since there is a positive value of starting the process at zero under IGBM.
} 
where $x_{2}^{*}$ solves the equation

$$
\frac{E^{\prime}\left(x_{2}^{*}\right)}{E\left(x_{2}^{*}\right)-(I-K)}=\frac{\psi^{\prime}\left(x_{2}^{*}\right)}{\psi\left(x_{2}^{*}\right)}
$$

which is determined via application of the smooth-pasting condition in Eq. (31).

Next, note that Eqs. (33) and (34) provide the second-best firm value and investment threshold conditional on the equityholders and debtholders agreeing on the periodic coupon payment $R$ in exchange for an initial loan of amount $K$. However, recall that debtholders rationally anticipate that equityholders will maximise equity value and will therefore charge appropriately high interest payments. In other words, the debtholders have no control over the equityholders' default and investment decisions but they can determine, given the coupon payment $R$, how much debt will be provided upon investment. Consequently, the fair value of debt, denoted as $K^{*}$ and representing the amount of debt provided at the time of investment, should be equal to Eq. (27) evaluated at the second-best investment threshold $x_{2}^{*}$, which yields ${ }^{20}$

$$
K^{*}=D\left(x_{2}^{*}\right)=\frac{R}{r}+\left((1-b) V_{u}\left(x_{d}^{*}\right)-\frac{R}{r}\right) \frac{\psi\left(x_{2}^{*}\right)}{\psi\left(x_{d}^{*}\right)} .
$$

Eq. (35) governs the equilibrium relationship between the coupon payment $R$ and the amount of debt provided. ${ }^{21}$ Given this relationship we can now determine the second-best firm value and threshold price in equilibrium. Substituting Eqs. (35) and (19) into Eqs. (33) and (34) yields

$$
F_{2}(x)= \begin{cases}\left(V_{\ell}\left(x_{2}^{*}\right)-I\right) \frac{\psi(x)}{\psi\left(x_{2}^{*}\right)}, & \text { for } x<x_{2}^{*}, \\ V_{\ell}(x)-I, & \text { for } x \geq x_{2}^{*}\end{cases}
$$

and furthermore

$$
\frac{E^{\prime}\left(x_{2}^{*}\right)}{V_{\ell}\left(x_{2}^{*}\right)-I}=\frac{\psi^{\prime}\left(x_{2}^{*}\right)}{\psi\left(x_{2}^{*}\right)} .
$$

\subsection{First-best investment policy}

The comparison of the results derived from Eqs. (36) and (37) to the first-best firm value and investment trigger price allows for a quantitative analysis of agency costs. We derive the first-best firm value and investment policy based on the setting in which the overall firm value, as opposed to equity value, is maximised. In this case, and analogous to the second-best value, the first-best firm value, $F_{1}(x)$, must satisfy the ODE

$$
\frac{1}{2} \sigma^{2} x^{2} F_{1}^{\prime \prime}(x)+(\eta(\bar{x}-x)-\lambda \rho \sigma x) F_{1}^{\prime}(x)-r F_{1}(x)=0
$$

\footnotetext{
${ }^{20}$ The rational debtholders could provide less debt for a given coupon payment $R$, however we assume that competition amongst debt providers will enforce the stated equality.

${ }^{21}$ Equivalently, one could solve (implicitly) for $R$ and determine the fair coupon payment debtholders would expect for a given amount of debt $K$ promised to equityholders at time of investment.
} 
subject to the boundary conditions

$$
\begin{aligned}
& F_{1}\left(x_{1}^{*}\right)=V_{\ell}\left(x_{1}^{*}\right)-I, \\
& \left.F_{1}^{\prime}(x)\right|_{x=x_{1}^{*}}=\left.V_{\ell}^{\prime}(x)\right|_{x=x_{1}^{*}}, \\
& \lim _{x \downarrow 0} F_{1}(x)<\infty,
\end{aligned}
$$

where $x_{1}^{*}$ denotes the first-best investment threshold. Condition (39) indicates that the first-best firm value upon investment is now the total levered project value in excess of the total investment cost to the firm (I). Once more, condition (40) is a smooth-pasting condition ensuring optimality of the investment threshold $x_{1}^{*}$ and Eq. (41) ensures that the firm value remains finite as $x$ approaches zero. Application of boundary conditions (39), (40) and (41) to the general solution of (38) yields the following first-best firm value:

$$
F_{1}(x)= \begin{cases}\left(V_{\ell}\left(x_{1}^{*}\right)-I\right) \frac{\psi(x)}{\psi\left(x_{1}^{*}\right)}, & \text { for } x<x_{1}^{*}, \\ V_{\ell}(x)-I, & \text { for } x \geq x_{1}^{*}\end{cases}
$$

where $x_{1}^{*}$ solves the equation

$$
\frac{V_{\ell}^{\prime}\left(x_{1}^{*}\right)}{V_{\ell}\left(x_{1}^{*}\right)-I}=\frac{\psi^{\prime}\left(x_{1}^{*}\right)}{\psi\left(x_{1}^{*}\right)}
$$

as determined by application of the smooth-pasting condition (39).

Remark 4. We note that the representation of the two firm values given by Eqs. (36) and (42) differ only by the critical level $x_{i}^{*}$ employed. Therefore, since the value of $F_{1}(x)$ was determined by maximisation of $\left(V_{\ell}\left(x_{i}\right)-I\right) \psi(x) / \psi\left(x_{i}\right)$ over all such investment triggers $x_{i}$, it must follow that, for a fixed coupon payment $R$, the second-best firm value $F_{2}(x)$ is always lower than (or equal to) the first-best value $F_{1}(x)$, i.e. $F_{2}(x) \leq F_{1}(x)$, for all $x$. Furthermore, since $F_{2}(x) \leq F_{1}(x)$ for all $x$, and both $F_{1}$ and $F_{2}$ dominate $V_{\ell}-I$, it is evident that the second-best investment trigger price always lies below the first-best investment trigger price, i.e. $x_{2}^{*} \leq x_{1}^{*}$, resulting in earlier (or over-) investment by levered firms (for a fixed coupon).

\subsection{Optimal financing}

The above analysis confirms the overinvestment of equityholders, however it is important to note that the above results only hold true for a coupon $R$ fixed across first- and second-best outcomes. In reality, equityholders are free to choose their financing strategy too, and hence the coupon payment $R$ which maximises equity value will not necessarily be the same as that which maximises total firm value. We thus define the optimal coupon payment which maximises the first- and second-best firm value as

$$
R_{i}^{*}=\arg \max _{R} F_{i}(x ; R), \quad \text { for } i=1,2 .
$$

From the problem formulation it seems clear that an optimal coupon payment exists due to the tradeoff between the expected benefits of the tax shields and the expected costs of financial distress, see Eq. (28). 


\subsection{Agency costs}

To quantify the agency cost of overinvestment by equityholders we follow Mauer and Sarkar (2005) and define the agency cost as the difference between first- and second-best firm values (evaluated at their respective optimal coupon payments) in percent of the second-best firm value;

$$
A C:=\frac{F_{1}\left(x ; R_{1}^{*}\right)-F_{2}\left(x ; R_{2}^{*}\right)}{F_{2}\left(x ; R_{2}^{*}\right)} .
$$

Mauer and Sarkar (2005) decompose agency cost into two components: the loss of pure operating value due to agency conflicts and the loss in the net benefit of debt financing. In contrast, and in order to quantify the agency costs due to differences in timing decisions ( $x_{1}^{*}$ vs. $\left.x_{2}^{*}\right)$ and those due to differences in financing decisions ( $R_{1}^{*}$ vs. $R_{2}^{*}$ ), we choose to define:

$$
A C=\left[\frac{F_{1}\left(x ; R_{1}^{*}\right)-F_{1}\left(x ; R_{2}^{*}\right)}{F_{2}\left(x ; R_{2}^{*}\right)}\right]+\left[\frac{F_{1}\left(x ; R_{2}^{*}\right)-F_{2}\left(x ; R_{2}^{*}\right)}{F_{2}\left(x ; R_{2}^{*}\right)}\right]=: A C^{f i n}+A C^{\text {tim }} .
$$

This novel decomposition provides additional insights and highlights important results when comparing GBM and mean reversion in Section 3.

Remark 5. It can easily be shown that $F_{1}\left(x ; R_{1}^{*}\right) \geq F_{1}\left(x ; R_{2}^{*}\right) \geq F_{2}\left(x ; R_{2}^{*}\right)$, where the first inequality must be true from the definition of $R_{1}^{*}$ and the second inequality is due to the dominance of $F_{1}$ over $F_{2}$ for any fixed coupon $R$. Hence it is clear that both $A C^{\text {fin }}$ and $A C^{t i m}$ are positive. Thus, for a fixed coupon payment $R$, the overinvestment of equityholders (i.e., their optimal timing decisions) results in a decrease in firm value. However, with the inclusion of the optimal financing policy (i.e., the choice of coupon $R$ ) the equityholders' optimal leverage decision results in an even further reduction in firm value. The absolute and relative size of these two agency cost components will be of primary interest in our results below.

\section{Results}

In this section we present results based on the IGBM process and, for comparison, a standard GBM process (obtained by setting $\bar{x}=0$ and $\eta=-\alpha$ ). After identifying our base-case parameters, we first briefly discuss the effects of mean reversion on the firm's optimal timing decisions for a fixed coupon rate $R$. Since the investment timing and financing decisions are intimately linked this partial analysis allows us to first isolate the effect of mean reversion on the firm's optimal timing decisions. We then consider the optimal coupon payment and the additional effect of mean reversion on the firm's optimal financing decisions. Finally we quantify the agency costs of debt financing (and its components) and perform extensive equilibrium comparative statics analysis for all model parameters, focusing in particular on the speed of mean reversion $\eta$, which plays a crucial role for our model results.

\subsection{Base-case parameters}

To illustrate the model we consider the investment into an oil production facility (such as an oil rig). Oil continues to be a key energy resource in the 21 st century and therefore has received much 
attention in the the real options literature (see, for example, Paddock, Siegel, and Smith, 1988). Furthermore, many studies indicate that oil price dynamics exhibit mean-reverting behaviour, at least over longer time periods (see Bessembinder et al., 1995).

We estimated the parameters of the IGBM model using approximately 15 years (January 2000October 2014) of monthly West Texas Intermediate (WTI) oil price data (U.S. Dollars per Barrel). ${ }^{22}$ We employed the estimation method of Longstaff and Schwartz (1995) (see also Insley, 2002, Sarkar and Zapatero, 2003, Hong and Sarkar, 2008) and the estimation yielded the following base-case uncertainty parameters: $\bar{x}=\$ 97.00, \eta=0.1703$ and $\sigma=0.265$.

The other (non-process specific) parameters are taken to be: $r=0.04, \lambda \rho=0.32, \tau=0.30$, $b=0.35, C=\$ 60, R=\$ 13.50, I=\$ 180$ and $X_{0}=\$ 100$, where all costs are in units of per barrel. The production cost of $\$ 60$ is set to be the average production cost (per barrel) for several oil production technologies (see International Energy Agency, 2008, p. 218). Note that these costs are less than the long-run price level $\bar{x}$ and so, in the absence of debt, the project is expected to make a profit in the long run. However, the parameters are such that it will be optimal to default for sufficiently low oil prices; see condition (23). The base-case coupon payment $R$ is derived as the optimal second-best coupon for the base-case parameters (in which $65.8 \%$ of the project is financed by debt). This choice is consistent with the procedure adopted in Mauer and Sarkar (2005) for choosing their base case. Since the cost of various oil production facilities vary so greatly we simply take the investment cost $I$ to be three times the production cost (per barrel). The effective tax rate $\tau$ of $30 \%$ and bankruptcy costs $b$ of 35\% follow Mauer and Sarkar (2005). Since the parameters $\lambda$ and $\rho$ only appear together as $\lambda \rho$ in the model, and furthermore since this quantity can be identified as the Sharpe ratio, ${ }^{23}$ we assume the value of $\lambda \rho$ to be 0.32 , taken from Henriques and Sadorsky (2008), who report the Sharpe ratio for oil prices over a similar sample period to ours. Finally, we take the initial oil price, $X_{0}$, to be $\$ 100$ which approximately reflects WTI oil prices during 2014, the final year of our estimation period. We note, however, that our optimal abandonment, default and investment trigger prices, as well as our leverage and creditspread results, are all independent of the chosen value of $X_{0}$. Furthermore, provided $X_{0}<x_{2}^{*}$, our valuation formulae (36) and (42) also imply that agency costs are independent of $X_{0}$.

\subsection{Comparative statics for a fixed coupon $R$}

In the following we fix the coupon $R$ to analyse the isolated effect of mean reversion on equityholders' optimal abandonment/default and the corresponding equilibrium debt provision. In Section 3.3 we extend this analysis to include the additional effect of the firm's optimal financing decisions and present the full equilibrium comparative statics of the model.

\section{Project and firm values}

Fig. 1 illustrates the unlevered and levered project values along with the project abandonment and default threshold prices for the base case. The unlevered project is optimally abandoned

\footnotetext{
${ }^{22}$ The oil price data was obtained from the U.S. Energy Information Administration and the prices were converted to real (October 2014) prices using the Producers Price Index (PPI) from the U.S. Bureau of Labor Statistics. The process was estimated using real prices since it is the real price (not the nominal) that is assumed to mean revert.

${ }^{23}$ Given the CAPM relationship used, i.e. $\mathbb{E}\left[R_{X}\right]=r+\lambda \rho \sigma\left(R_{X}\right)$, where $R_{X}$ denotes the return on the output price $X$, we observe that $\lambda \rho=\left(\mathbb{E}\left[R_{X}\right]-r\right) / \sigma\left(R_{X}\right)$, which can be identified as the Sharpe ratio of the asset $X$.
} 
at an oil price of $\$ 25.75$, whereas the addition of leverage increases this threshold to $\$ 50.18$, thereby confirming that $x_{a}^{*} \leq x_{d}^{*}$. We note that $x_{a}^{*}$ is very low compared to the prices observed during the data sample period, indicating that reaching this level would be highly unlikely if the price dynamics continued as in the sample period. On the other hand, $x_{d}^{*}$ is almost twice as large, indicating a much higher probability of default due to the effect of debt on the project cash flows. ${ }^{24}$ We also note that for the base-case parameters $V_{\ell}\left(X_{0}\right)=\$ 177.98$ and $V_{u}\left(X_{0}\right)=\$ 168.325$, hence debt financing adds $\$ 9.65$ (or $5.73 \%$ ) to the total project value, reflecting the expected value of the tax shield in excess of bankruptcy costs.

\section{*** Insert Figures 1 and 2 about here ***}

Fig. 2 illustrates the first- and second-best firm values. The first-best firm value $F_{1}(x)$ is clearly greater than the second-best firm value $F_{2}(x)$, with the difference reflecting the agency cost of debt financing. Overinvestment is also observed since $x_{2}^{*} \leq x_{1}^{*}$.

\section{Abandonment and default thresholds}

The threshold price of the equityholders' abandonment/default option is of utmost importance in the model since it governs the investor's optimal behaviour after investment which, in turn, influences the rational debtholders' behaviour and hence the magnitude of agency costs. Key drivers for these threshold prices are the parameters of the mean-reverting process employed (i.e., $\bar{x}, \eta$ and $\sigma$ ). Comparative statics for the threshold levels $x_{a}^{*}$ and $x_{d}^{*}$ are presented in Fig. 3. In addition, the non-process-dependent discount parameters $r, \lambda$ and $\rho$, and the cost parameter $C$ are also presented. We note that Eqs. (16) and (22) indicate that the abandonment and default threshold prices are independent of the parameters $b$ and $\tau$.

\section{$* * *$ Insert Figure 3 about here $* * *$}

Once more, Fig. 3 demonstrates that $x_{a}^{*} \leq x_{d}^{*}$ for all parameter values. In addition, for higher $\bar{x}$, lower costs $C$, or a lower discount rate (due to a lower $r, \lambda$ or $\rho$ ), abandonment and default occurs at a lower price because the valuation of the project increases in these cases. Project owners therefore tolerate much lower output prices in light of this increased valuation.

From Fig. 3(b) we also observe that a higher speed of mean reversion results in a lower abandonment or default threshold. This result can be understood by recalling that the long-run profitability of the production facility is positive (i.e., $\bar{x}>C+R$ ) and so higher levels of $\eta$ indicate that price departures from $\bar{x}$ (and hence from a profitable region) are corrected more quickly through a

\footnotetext{
${ }^{24}$ Subsequent to our estimation and the preparation of this paper, the precipitous fall in world oil prices (to below $\$ 30$ at the time of writing) suggests the realistic possibility of abandonment and default on oil production facilities. In fact, this appears to be exactly what is happening, see, for example, http://money.cnn.com/2016/01/22/ investing/oil-crisis-defaults-rise/.
} 
stronger mean-reversion force. This reduces the price variance and the equityholders' are willing to tolerate lower output prices. We note that this $\eta$ dependence, however, is qualitatively different when the project is not expected to be profitable in the long-run (i.e., when $\bar{x}<C+R$ ). In this case we find that an increase in the speed of mean reversion actually increases the abandonment and default thresholds, and hence increases the probability of such default (which in turn would impact debt provision and the equilibrium outcome). ${ }^{25}$ This result emphasises the importance of the long-run profitability on the model outcomes which will be discussed further in Section 3.4 (see Result 2).

Fig. 3 also reveals that for certain parameter regimes it is optimal to never abandon or default on the project (i.e., $x_{a}^{*}=0$ or $x_{d}^{*}=0$, respectively), see Remark 3. No-default regions occur for very profitable projects, when either $\bar{x}$ is high or costs $C$ are low. No default or abandonment also becomes optimal for sufficiently low volatility $\sigma$, market price of risk $\lambda$, or correlation $\rho$, or for sufficiently high speeds of mean reversion $\eta$, since these scenarios describe an increased certainty in price and hence an increase in valuation.

Remark 7. The critical parameter values which separate the default versus no-default regions can be determined by rearranging the equality in Eq. (23) for the required parameter. For example, the critical value of $\eta$ above which the investor would never default on the project in Fig. 3(b) can be calculated as $\eta^{*}:=(r+\lambda \rho \sigma)(C+R) /(\bar{x}-C-R) \simeq 0.39$ with the associated critical value for abandonment obtained by setting $R=0$ to yield $\eta^{*} \simeq 0.2$.

Finally, when considering the effects of $\sigma$ on equityholders' timing, it is well understood that (in the absence of risk discounting) an increase in volatility $(\sigma)$ would result in an increase in the value of the default and abandonment options, with an associated decrease in the default and abandonment threshold prices. However, the inclusion of the risk-discounting effect results in the additional impact of volatility on the required rate of return which has a competing effect on the default and abandonment thresholds. An increase in $\sigma$ results in a higher risk-adjusted discount rate and hence a lower option/project value and a higher threshold price. These two competing forces explain the observed $\sigma$ comparative statics shown in Fig. 3(c), which indicates that the risk-discounting effect dominates for low volatilities.

\section{Equilibrium debt provision}

Next, we briefly discuss the equilibrium provision of debt when cash flows are mean reverting. Fig. 4 shows the equilibrium amount of debt financing for a given coupon payment $R$. Whilst it is not surprising that more debt is provided as the coupon payment $R$ increases, the concavity of the relationship reveals the impact of the increased credit risk to the debt providers as $R$, and therefore the amount of debt, increases. Higher coupon payments put the firm in a worse financial position, burdened with a higher financing cost, which increases the probability of equityholders' default.

*** Insert Figure 4 about here ***

\footnotetext{
${ }^{25}$ Specifically, it can be shown that $\frac{\partial x_{d}^{*}}{\partial \eta}=-\frac{(1-\tau)(\bar{x}-C-R) \phi^{\prime}\left(x_{d}^{*}\right)}{r(r+\eta+\lambda \rho \sigma) \phi^{\prime \prime}\left(x_{d}^{*}\right) f_{\ell}\left(x_{d}^{*}\right)}$, hence $x_{d}^{*}$ is decreasing in $\eta$ for $\bar{x}>C+R$ and increasing for $\bar{x}<C+R$.
} 
In equilibrium the debtholders are very reluctant to provide debt in excess of the investment amount $I$ (i.e., $K^{*}>I$ ). This result differs from the results of Mauer and Sarkar (2005), since for their base case a particularly high value of debt financing in equilibrium is observed (equal to an amount exceeding 2.75 times the investment cost). Our model generates perhaps more realistic equilibrium debt levels for economically reasonable annual coupon payments, where the first- and second-best optimal coupons, $R_{1}^{*}=\$ 16.31$ and $R_{2}^{*}=\$ 13.50$ correspond to an equilibrium debt financing of $74.2 \%$ and $65.8 \%$ of the project cost, respectively.

\subsection{Full comparative statics}

We now proceed to investigate the influence of mean reversion when the additional flexibility of equityholders to select the optimal coupon payment $R^{*}$ is taken into account.

\section{Investment thresholds}

Fig. 5 plots the investment threshold prices $x_{i}^{*}(i=1,2)$ for varying model parameters, along with the abandonment and default threshold prices $x_{a}^{*}$ and $x_{d}^{*}$ for comparison.

*** Insert Figure 5 about here $* * *$

We observe that $x_{2}^{*}<x_{1}^{*}$ for all model parameters indicating that overinvestment is maintained by equityholders when they are also allowed to optimally choose the level of debt financing (see Remark 4). Fig. 5 also shows that the investment thresholds decrease for higher long-run price levels $\bar{x}$ and a higher speed of mean reversion $\eta$. The opposite relationship holds when considering the optimal investment thresholds and $\sigma, r, \lambda, \rho, C, \tau, b$ or $I$.

Perhaps the most striking observation from Fig. 5 is that for some parameter regimes (high $\bar{x}$ and $\eta$, as well as low $\sigma, \lambda, \rho$ and $C$ ) the first- and second-best investment threshold prices appear to converge, resulting in very similar first- and second-best outcomes. ${ }^{26}$ This indicates that the agency cost is very low in these regimes. Indeed, inspection of Eqs. (37) and (43), reveals that threshold prices $x_{1}^{*}$ and $x_{2}^{*}$ are equal when $V_{\ell}^{\prime}(x)=E^{\prime}(x)$, i.e. if $D^{\prime}(x)=0$ and hence the value of debt is insensitive to the cash flow level. We thus infer that in these parameter regimes debtholders are not concerned with equityholders' default since the project's cash flows are such that it is optimal for equityholders to default at very low output prices.

To better understand the two apparent regimes of equilibrium behaviour we choose to focus on the speed of mean reversion parameter $\eta$. Furthermore, recall that $\eta=0$ corresponds to (driftless) GBM dynamics and so considering the $\eta$ dependence also allows us to compare the results under mean reversion with standard GBM. Fig. 6 shows the full comparative statics (allowing for the change in optimal coupon) of several equilibrium outputs as $\eta$ is varied. Fig. 6(a) shows the equilibrium outcome for the optimal coupon rate, Figs. 6(b), 6(c), and 6(d) show the equilibrium debt level, equity level and leverage ratio ${ }^{27}$ at time of investment, and Fig. 6(e) shows the equilibrium

\footnotetext{
${ }^{26}$ Upon closer inspection these values are not identically equal. However the percentage difference in values are much less than $1 \%$ in this regime.

${ }^{27}$ Defined as $L_{i}^{*}=K_{i}^{*} / V_{\ell}\left(x_{i}^{*} ; R_{i}^{*}\right)$ for $i=1,2$.
} 
credit spreads, defined as $C S_{i}=R_{i}^{*} / K_{i}^{*}-r$ for $i=1,2$, which acts as a proxy for the willingness of the debtholders to provide debt in equilibrium. In addition, Table 1 reports comparative statics results for these equilibrium outcomes (plus agency costs) for all model parameters.

*** Insert Figure 6 and Table 1 about here ***

Firstly, from Fig. 6(a) we observe that the equilibrium first-best coupon, $R_{1}^{*}$, is higher than the second-best outcome, $R_{2}^{*}$. Therefore, equityholders maximising equity value invest sooner and also pick a lower coupon than a manager maximising total firm value; the overall effect is to increase agency costs (over that with a fixed coupon rate across first- and second-best optimisers). The lower second-best coupon rate also results in a lower amount of debt and leverage ratio at the time of investment-see Figs. 6(b) and 6(d). Economically, the incentive for the first-best optimiser to take on more debt is a result of the substantial benefits of the tax shield in increasing total firm value.

Secondly, recall that for the base-case parameters we have $\bar{x}-C=\$ 37$, hence the project is profitable in the long-run in the absence of any debt. Consequently, the firm can take on a coupon payment of up to $\$ 37$ and still remain profitable in the long-run. Inspection of Fig. 6(a) indicates that the coupon payment for the second-best outcome is indeed always below this maximum value. ${ }^{28}$

Finally, Fig. 6 clearly demonstrates the existence of two distinct regimes of equilibrium behaviour. The first regime, for $\eta$ smaller than a critical value $\eta_{c}$, exhibits decreasing coupon payments and debt levels, decreasing and then increasing equity levels, and high (but decreasing) credit spreads. In the second regime, for $\eta>\eta_{c}$, coupon payments and debt levels are now both increasing, equity levels are decreasing, and credit spreads are now extremely low. For the base-case parameters we observe that $\eta_{c} \simeq 0.184$.

Result 1. There are two distinct regimes of equilibrium (financing and timing) behaviour as the speed of mean reversion $\eta$ varies.

The non-monotonicity of the model outcomes with respect to $\eta$ can be seen as a consequence of the strategic interaction between equity- and debtholders. Firstly we note that as $\eta$ increases the variance of the project cash-flows will decrease; since departures from the long-run mean $\bar{x}$ become less likely. All else being equal, this reduced variance increases the perceived safety of the project and hence the credit spreads offered by debtholders are lowered as $\eta$ becomes largersee Fig. 6(e). Cheaper debt provides a clear incentive for equityholders to increase the amount of debt used to finance the project. However, whilst this is exactly what we observe in the high $\eta$ regime (where credit spreads are extremely low), in the low $\eta$ regime the amount of debt actually decreases as $\eta$ is increased above zero-see Fig. 6(b).

\footnotetext{
${ }^{28}$ The first-best outcome does optimally make the project loss-making in the long run for very low speeds of mean reversion. However as $\eta \rightarrow 0$ convergence to the long-run level is very slow and the effect of $\bar{x}$ essentially disappears.
} 
In order to shed some light onto this initial decrease, we observe that the equity valuation at the time of investment-Fig. 6(c)—also decreases as $\eta$ is increased above zero, providing equityholders with an incentive to reduce the amount of debt taken on board. The initial decrease in equity value is due to a reduction in value of the equityholders' option to default on the levered project; since a reduced variance is well known to reduce option values (see, for example, Bergman, Grundy, and Wiener, 1996). As $\eta$ continues to increase, however, the cash-flow variance decreases to a point where the value of the default option is very small and cannot be reduced any further. Given that the credit spreads are also very small here, an increase in $\eta$ now has the overall effect of increasing the optimal debt level (and leverage ratio) in equilibrium, utilizing the more valuable tax shield.

Finally, it is also interesting to note that the optimal coupon payment never reduces to zero in equilibrium, since there always remains some tax-shield benefits to the equityholders. A surprising implication of this being that it is always optimal for equityholders to default on the project in equilibrium, even for very high values of $\eta$. As $\eta$ increases to the region in which it would be optimal to never default for a fixed coupon payment—see Fig. 3(b) - the equityholders dramatically increase their coupon payment so that default still remains optimal at sufficiently low prices. Economically this implies that there is always some incentive for the equityholders to transfer wealth from the debtholders.

\subsection{Agency costs and decomposition}

This section analyses the magnitude of agency costs and its components. Table 1 reveals that our comparative statics results for the financing parameters ( $b$ and $\tau$ ) and the discount parameters $(r, \lambda$ and $\rho$ ) are consistent with Mauer and Sarkar (2005). However, the consideration of meanreverting dynamics provides us with new results in regards to the effect of the process parameters $(\bar{x}, \eta$, and $\sigma)$ on the magnitude of agency costs.

Firstly, when considering $\bar{x}$ we previously observed that a key driver for the qualitative behaviour of the model's output is the long-run profit margin of the project $\bar{x}-C$, which increases when either $\bar{x}$ increases or costs $C$ decrease. Accordingly, inspection of Table 1 provides the following result:

Result 2. As the long-run profitability of the project increases, agency costs are reduced. Furthermore, agency costs become negligible above a critical profit margin.

Secondly, when considering the agency cost as a function of the speed of mean reversion $\eta$, we also observe that the agency costs decrease as $\eta$ increases and further that the agency costs are negligible above the critical value $\eta_{c}{ }^{29}$ This result is consistent with the apparent convergence of the first- and second-best investment threshold prices observed in Fig. 5(b). Perhaps more importantly, the dependence of agency costs on $\eta$ also allows us to compare the magnitude of such costs under mean-reverting dynamics (i.e., $\eta>0$ ) with those under GBM dynamics (i.e.,

\footnotetext{
${ }^{29}$ Note, however, that since it remains optimal for equityholders' to default for sufficiently low prices for all $\eta$ (see the final paragraph of Section 3.3) a small amount of agency cost still remains above the critical value of $\eta$. However, the optimal default prices are so small that the probability of default, and hence the magnitude of the agency cost, is negligible in this regime $(<0.001 \%)$.
} 
$\eta=0$ ). We observe that under mean reversion the total agency cost is $1.02 \%$ (for our base-case parameters). In comparison, the (driftless) GBM case has a total agency cost of $8.46 \%$. Therefore, we now state our main result:

Result 3. Agency costs are lower under mean-reverting output cash flows when compared to geometric Brownian motion for the same $\sigma$.

In fact, the above result also remains valid when we consider the agency costs for GBM processes with non-zero drift; obtained by setting $\bar{x}=0$ and $\eta=-\alpha$, where $\alpha$ denotes the drift of the GBM process. Comparative statics results for varying $\alpha$ can be found at the bottom of Table 1 and reveal that the total agency cost under GBM dynamics is remarkably insensitive to the drift of the GBM process employed; with agency costs only varying from $8.3 \%$ to $8.5 \%$ for a wide range of $\alpha$. We note that this magnitude of agency cost is comparable to the value found by Mauer and Sarkar (2005) who report a 9.5\% cost for their base-case results. ${ }^{30}$ Our conclusion from Result 3 is that the magnitude of the agency costs in our model appears to be significantly affected by the stationarity of the cash flow dynamics, with a higher cost associated with non-stationarity.

Thirdly, in regards to the effect of the volatility parameter, we observe that agency costs are reduced as $\sigma$ is decreased. The interpretation of this result is similar to above as the variance of the project cash-flows decreases as either $\eta$ is increased or $\sigma$ is decreased.

Finally, we consider the decomposition of the total agency cost into the two components, as defined by Eq. (46). Fig. 7 plots these components of agency cost as a function of the speed of mean reversion $\eta$. In addition, Table 2 also shows the agency cost decomposition as other model parameters are varied.

*** Insert Figure 7 and Table 2 about here ***

Consistent with Result 3, we see that the total agency cost decreases (approximately linearly) as the speed of mean reversion increases. However this total cost is not evenly distributed between those due to timing decisions and those due to financing decisions, yielding the following important result:

Result 4. For high speeds of mean reversion, $\eta$, agency costs are driven mainly by suboptimal timing decisions as opposed to suboptimal financing decisions.

Consistent with Remark 5, we observe that the agency cost due to both financing and timing decisions are positive. For $\eta=0$, corresponding to GBM dynamics, the total agency cost is roughly split between the financing and timing components. However as $\eta$ increases-resulting in the process becoming stationary-the impact of (suboptimal) timing decisions start to become more important relative to (suboptimal) financing decisions.

\footnotetext{
${ }^{30}$ We note that Leland (1998) only found around a $1 \%$ loss in firm value due to overinvestment for his base-case parameters under GBM. However, Leland (1998) did not account for the effect of capital structure on firm valuation whereas Mauer and Sarkar (2005) and our analysis do.
} 
*** Insert Figure 8 about here ***

Finally, given the stability of the total agency cost under GBM dynamics as the drift parameter $\alpha$ is varied, it is interesting to perform the agency decomposition for the GBM results for various values of $\alpha$. The results of this decomposition can be found in Fig. 8 and from which we conclude:

Result 5. Under GBM dynamics, the agency cost due to suboptimal financing decisions increases as the growth rate $\alpha$ increases whereas the agency cost due to suboptimal timing decisions decreases, resulting in a fairly constant total agency cost.

Results 4 and 5 suggest that the expected long-run growth prospects of the project have a significant impact on the nature of the agency cost, whereas the total magnitude of this cost is related to the stationarity of the project's cash flow. More specifically, for low or no growth projects (i.e., GBM dynamics with small or negative drifts, or MR dynamics with positive $\eta$ ) the agency conflicts over investment timing appear more important than those over financing. Conversely, for high growth projects (i.e., GBM dynamics with large positive drifts) conflicting views on the project's financing appear to be the dominant source of the agency cost.

\section{Conclusions}

This paper documents that the choice of the uncertainty process used to model investment project cash flows can have a significant impact on investment timing and related project financing decisions. The application of a mean-reverting (MR) process to our proposed model reveals important equilibrium results with respect to the investment, default, and financing strategies of equityholders, as well as the optimal debt provision of rational debtholders.

Under MR dynamics debtholders are very reluctant to provide more funding than the purchase price of the project, a result more consistent with observed investment practice than the existing geometric Brownian motion (GBM) based results. Furthermore, we observe two distinct regimes of equilibrium behaviour (dependent on parameters) demonstrating the increased complexity of the equilibrium financing and investment outcomes in the presence of MR dynamics.

In regards to the reduction in firm value due to agency conflicts (the agency costs), our results indicate that total agency costs are lower for a higher speed of mean reversion and also for a higher long-run profitability of the debt-financed project. Moreover, due to a novel agency cost decomposition, we show that under low-growth cash flows (modelled using MR dynamics or GBM with small or negative drifts) agency costs are driven mainly by equityholders' timing decisions rather than due to their financing decisions. On the other hand, for high-growth projects (modelled using GBM with large positive drifts) it is the equityholders' financing decisions that contribute the greatest to agency costs. Assuming a desire to decrease agency costs in an economy, the above information about the underlying components and drivers of such agency costs would be valuable to both policy makers and regulators alike.

Future work in this area can include the extension of the current analysis to firms that have existing operations financed with pre-existing debt, therefore analysing the effect of mean reversion on possible underinvestment and the related debt overhang problem (see Moyen, 2007). The 
inclusion of some information asymmetry between equityholders and debtholders could also be another direction for future research and more technical extensions could include accounting for jumps in the underlying price dynamics.

\section{Acknowledgements}

We thank Dirk Baur, Mingliang Cheng, Carl Chiarella, Geoff Evatt, Tony He, Hardy Hulley, Susan Thorp, Sherrill Shaffer, Frederic Sterbenz, Elizabeth Whalley, and the conference participants at the 2011 IFABS conference in Rome, the 2011 QMF conference in Sydney, the 2013 EFMA conference in Reading, and the 2014 SIAM conference on Financial Mathematics and Engineering in Chicago for their many useful and insightful comments. The comments from two anonymous referees and an Associate Editor are also gratefully acknowledged. Finally, research funding from the UTS Business School is kindly noted.

\section{References}

Abadie, L., Chamorro, J., 2008. Valuing flexibility: The case of an integrated gasification combined cycle power plant. Energy Economics 30, 1850-1881.

Abramowitz, M., Stegun, I. A., 1972. Handbook of Mathematical Functions with Formulas, Graphs, and Mathematical Tables. National Bureau of Standards Applied Mathematics Series 55, New York.

Baxter, N. D., 1967. Leverage, risk of ruin and the cost of capital. Journal of Finance 22, 395-403.

Bergman, Y. Z., Grundy, B. D., Wiener, Z., 1996. General properties of option prices. Journal of Finance 51, 15731610.

Bessembinder, H., Coughenour, J. F., Seguin, P. J., Smoller, M. M., 1995. Mean reversion in equilibrium asset prices: Evidence from the futures term structure. Journal of Finance 50, 361-375.

Bhattacharya, S., 1978. Project valuation with mean-reverting cash flow streams. Journal of Finance 33, $1317-1331$.

Black, F., Scholes, M., 1973. The pricing of options and corporate liabilities. Journal of Political Economy 81, 637654.

Brennan, M. J., Trigeorgis, L., 2000. Real options: Development and contributions. In: Brennan MJ \& Trigeorgis L (eds.) Project flexibility, agency, and competition: New developments in the theory and application of real options, $1-10$.

Cadenillas, A., Cvitanic, J., Zapatero, F., 2004. Leverage decision and manager compensation with choice of effort and volatility. Journal of Financial Economics 73, 71-92.

Coddington, E. A., Levinson, N., 1955. Theory of ordinary differential equations. Tata McGraw-Hill Education.

Cox, J., 1975. Notes on option pricing I: Constant elasticity of diffusions. Working paper, Stanford University.

Cox, J. C., Ingersoll, J. E., Ross, S. A., 1985. A theory of the term structure of interest rates. Econometrica 53, 385-407.

Dixit, A. K., Pindyck, R. S., 1994. Investment Under Uncertainty. Princeton University Press, Princeton, NJ.

Duffie, D., 1998. Securities Markets: Stochastic Models. Academic Press, San Diego, CA.

Ewald, C. O., Wang, W. K., 2010. Irreversible investment with Cox-Ingersoll-Ross type mean reversion. Mathematical Social Sciences 59, 314-318.

Fama, E. F., French, K. R., 2000. Forecasting profitability and earnings. Journal of Business 73, 161-176.

Freeman, R., Ohlson, J., Penman, S., 1982. Book rate of return and prediction of earnings changes: An empirical investigation. Journal of Accounting Research 2, 639-653.

Glover, K. J., Hambusch, G., 2014. The trade-off theory revisited: On the effect of operating leverage. International Journal of Managerial Finance 10, 2-22.

Gordon, M. J., 1959. Dividends, earnings, and stock prices. The Review of Economics and Statistics 41, 99-105.

Henriques, I., Sadorsky, P., 2008. Oil prices and the stock prices of alternative energy companies. Energy Economics 30, 998-1010. 
Hong, G., Sarkar, S., 2008. Commodity betas with mean reverting output prices. Journal of Banking and Finance 32 , 1286-1296.

Huang, C.-F., Litzenberger, R. H., 1990. Foundations for Financial Economics. Elsevier Science Publishers, New York, NY.

Insley, M., 2002. A real option approach to the valuation of a forestry investment. Journal of Environmental Economics and Management 44, 471-492.

International Energy Agency, 2008. World Energy Outlook 2008. Available from http://www.worldenergyoutlook.org.

Jensen, M. C., Meckling, W. H., 1976. Theory of the firm: Managerial behavior, agency costs and ownership structure. Journal of Financial Economics 3, 305-360.

Karlin, S., Taylor, H., 1999. A Second Course in Stochastic Processes. Academic press.

Kashyap, A., Rajan, R., Stein, J., 2002. Banks as liquidity providers: An explanation for the co-existence of lending and deposit-taking. Journal of Finance 57, 33-73.

Kormendi, R., Lipe, R., 1987. Earnings innovations, earnings persistence, and stock returns. Journal of Business 60, 323-346.

Kraus, A., Litzenberger, R. H., 1973. A state-preference model of optimal financial leverage. Journal of Finance 28, 911-922.

Leland, H. E., 1998. Agency costs, risk management, and capital structure. The Journal of Finance 53, $1213-1243$.

Linetsky, V., 2004. The spectoral decomposition of the option value. International Journal of Theoretical and Applied Finance 7, 337-384.

Longstaff, F., Schwartz, E., 1995. Valuing credit derivatives. Journal of Fixed Income 5, 6-12.

Lund, D., 1993. The lognormal diffusion is hardly an equilibrium price process for exhaustible resources. Journal of Environmental Economics and Management 25, 235-241.

Mauer, D. C., Ott, S. H., 2000. Agency costs, underinvestment, and optimal capital structure: The effect of growth options to expand. In: Brennan MJ \& Trigeorgis L (eds.) Project flexibility, agency, and competition: New developments in the theory and application of real options, 151-180.

Mauer, D. C., Sarkar, S., 2005. Real options, agency conflicts, and optimal capital structure. Journal of Banking and Finance 29, 1405-1428.

Merton, R. C., 1973. An intertemporal capital asset pricing model. Econometrica 41, 867-887.

Metcalf, G. E., Hassett, K. A., 1995. Investment under alternative return assumptions: Comparing random walks and mean reversion. Journal of Economic Dynamics and Control 19, 1471-1488.

Modigliani, F., Miller, M. H., 1959. The cost of capital, corporation finance, and the theory of investment: Reply. American Economic Review 49, 655-669.

Morellec, E., 2004. Can managerial discretion explain observed leverage ratios? Review of Financial Studies 17, 257-294.

Moyen, N., 2007. How big is the debt overhang problem? Journal of Economic Dynamics and Control 31, $433-472$.

Paddock, J. L., Siegel, D. R., Smith, J. L., 1988. Option valuation of claims on real assets: The case of offshore petroleum leases. Quarterly Journal of Economics 103, 479-508.

Raymar, S., 1991. A model of capital structure when earnings are mean reverting. Journal of Financial and Quantitative Analysis, 327-344.

Sarkar, S., 2003. The effect of mean reversion on investment under uncertainty. Journal of Economic Dynamics and Control 28, 377-396.

Sarkar, S., Zapatero, F., 2003. The trade-off model with mean reverting earning: Theory and empirical tests. The Economic Journal 113, 834-860.

Schwartz, E. S., 1997. The stochastic behavior of commodity prices: Implications for valuation and hedging. Journal of Finance 52, 923-973.

Titman, S., Tsyplakov, S., 2007. A dynamic model of optimal capital structure. Review of Finance 11, 401-451.

Tsekrekos, A. E., 2010. The effect of mean reversion on entry and exit decision under uncertainty. Journal of Economic Dynamics and Control 34, 725-742.

Tsekrekos, A. E., 2013. Irreversible exit decisions under mean-reverting uncertainty. Journal of Economics 110, 5-23.

Zhao, B., 2009. Inhomogeneous geometric Brownain motions. Working paper, City University, London. 


\section{Appendix A. Derivation of the solution to Eq. (12)}

We transform Eq. (12) to the standard form of the so-called Kummer's equation for which the solutions are well understood (Abramowitz and Stegun, 1972, Chapter 13). To do this we first let $u(x)=x^{\gamma} v(x)$, where $\gamma$ is to be determined, and then let $z=2 \eta \bar{x} / \sigma^{2} x$ to yield

$$
z v^{\prime \prime}(z)+\left(2-2 \gamma+\frac{2(\eta+\lambda \rho \sigma)}{\sigma^{2}}-z\right) v^{\prime}(z)+\left(\gamma+\frac{1}{z}\left((\gamma-1) \gamma-\frac{2 \gamma(\eta+\lambda \rho \sigma)-2 r}{\sigma^{2}}\right)\right) v(z)=0 .
$$

The next step is to choose $\gamma$ such that

$$
\frac{1}{2} \sigma^{2} \gamma(\gamma-1)-\gamma(\eta+\lambda \rho \sigma)-r=0
$$

to obtain

$$
z v^{\prime \prime}(z)+(n-z) v^{\prime}(z)-m v(z)=0,
$$

which we identify as Kummer's equation with $n=2-2 \gamma+\frac{2(\eta+\lambda \rho \sigma)}{\sigma^{2}}$ and $m=-\gamma$. It is well known that Eq. (A.2) has two independent solutions $v(z)=U(m, n ; z)$ and $v(z)=M(m, n ; z)$ which are called, respectively, Tricomi's and Kummer's confluent hypergeometric functions. If $m>0$ (hence $\gamma<0)$ then it can be shown that $U$ and $M$ are positive with $U(m, n ; z)$ strictly decreasing, and $M(m, n ; z)$ strictly increasing, in $z$. It can furthermore be verified that $\phi(x)$ and $\psi(x)$ are strictly decreasing and increasing in $x$, respectively (details are available from the authors upon request). Therefore we take $\gamma$ to be the negative root of Eq. (A.1).

\section{Appendix B. Derivation of Eq. (28)}

To derive Eq. (28) we first substitute Eqs. (20) and (27) into Eq. (19) and rearrange to yield

$$
\begin{aligned}
V_{\ell}(x) & =E(x)+D(x) \\
& =f_{\ell}(x)-f_{\ell}\left(x_{d}^{*}\right) \frac{\phi(x)}{\phi\left(x_{d}^{*}\right)}+\frac{R}{r}+\left((1-b) V_{u}\left(x_{d}^{*}\right)-\frac{R}{r}\right) \frac{\phi(x)}{\phi\left(x_{d}^{*}\right)} \\
& =-\underbrace{b V_{u}\left(x_{d}^{*}\right) \frac{\phi(x)}{\phi\left(x_{d}^{*}\right)}}_{\mathrm{PV} \text { of bankruptcy cost }}+f_{\ell}(x)-f_{\ell}\left(x_{d}^{*}\right) \frac{\phi(x)}{\phi\left(x_{d}^{*}\right)}+\frac{R}{r}+\left(V_{u}\left(x_{d}^{*}\right)-\frac{R}{r}\right) \frac{\phi(x)}{\phi\left(x_{d}^{*}\right)} .
\end{aligned}
$$

Using $f_{\ell}(x)=f_{u}(x)-R(1-\tau) / r$ yields

$$
V_{\ell}(x)=-b V_{u}\left(x_{d}^{*}\right) \frac{\phi(x)}{\phi\left(x_{d}^{*}\right)}+f_{u}(x)-f_{u}\left(x_{d}^{*}\right) \frac{\phi(x)}{\phi\left(x_{d}^{*}\right)}+\underbrace{\frac{\tau R}{r}\left(1-\frac{\phi(x)}{\phi\left(x_{d}^{*}\right)}\right)}_{\mathrm{PV} \text { of tax shield }}+V_{u}\left(x_{d}^{*}\right) \frac{\phi(x)}{\phi\left(x_{d}^{*}\right)} .
$$


Finally we recall from Eq. (15) that $V_{u}\left(x_{d}^{*}\right)=f_{u}\left(x_{d}^{*}\right)-f_{u}\left(x_{a}^{*}\right) \frac{\phi\left(x_{d}^{*}\right)}{\phi\left(x_{a}^{*}\right)}$ and substituting into (B.1) yields

$$
\begin{aligned}
V_{\ell}(x) & =f_{u}(x)-f_{u}\left(x_{a}^{*}\right) \frac{\phi(x)}{\phi\left(x_{a}^{*}\right)}+\frac{\tau R}{r}\left(1-\frac{\phi(x)}{\phi\left(x_{d}^{*}\right)}\right)-b V_{u}\left(x_{d}^{*}\right) \frac{\phi(x)}{\phi\left(x_{d}^{*}\right)} \\
& =V_{u}(x)+\frac{\tau R}{r}\left(1-\frac{\phi(x)}{\phi\left(x_{d}^{*}\right)}\right)-b V_{u}\left(x_{d}^{*}\right) \frac{\phi(x)}{\phi\left(x_{d}^{*}\right)}
\end{aligned}
$$

as stated. 


\section{Figures}

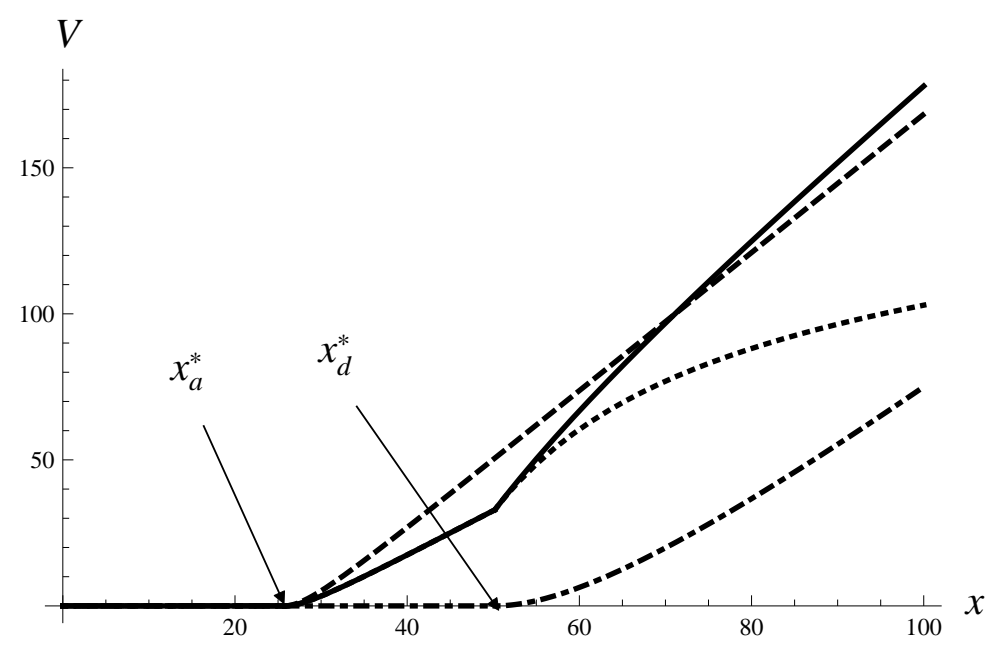

Figure 1: Unlevered and levered project values $V_{u}(x)$ and $V_{\ell}(x)$ as a function of the initial output price $x$ (solid line $=$ $V_{\ell}(x)$, dashed line $=V_{u}(x)$, dotted line $=D(x)$, dot-dashed line $=E(x)$; for base-case parameters $)$.

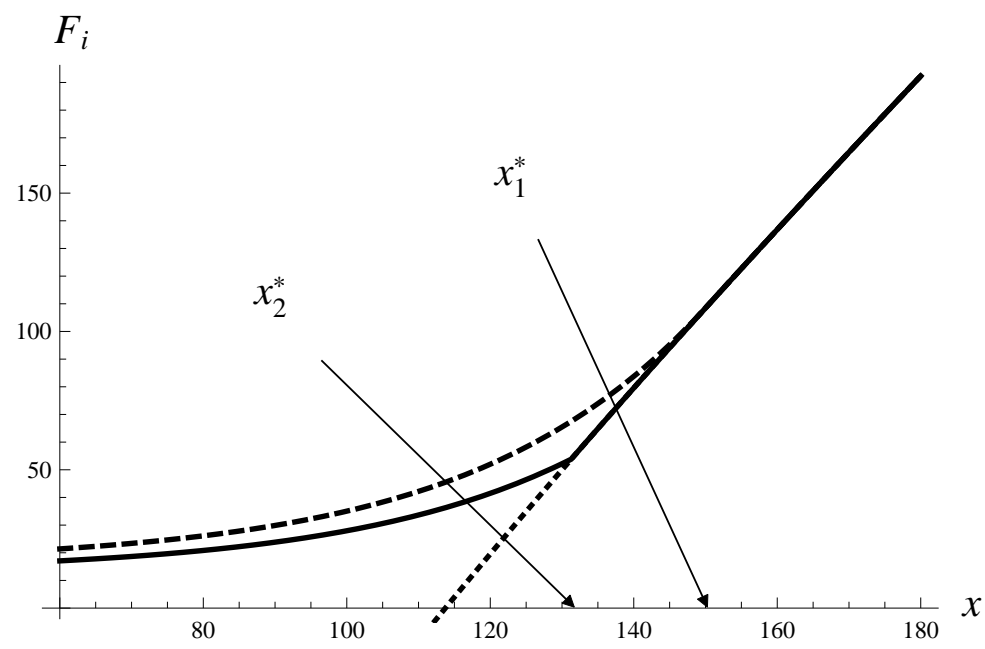

Figure 2: Value of the first- and second-best investment option $\left(F_{1}\right.$ and $\left.F_{2}\right)$ as a function of the initial output price $x$ (solid line $=$ second-best option $F_{2}$, dashed line $=$ first-best option $F_{1}$, dotted line is the value of the levered firm $V_{\ell}(x)$ less investment cost $I$; for base-case parameters - except we use $R=\$ 50$ for emphasis). Note the smooth pasting of the first-best outcome but not the second best, demonstrating optimally of the first-best timing decision and the suboptimality of the second-best. 


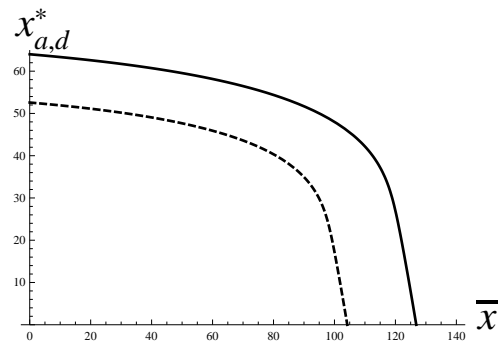

(a)

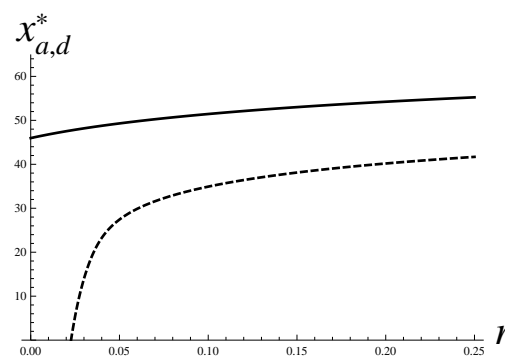

(d)

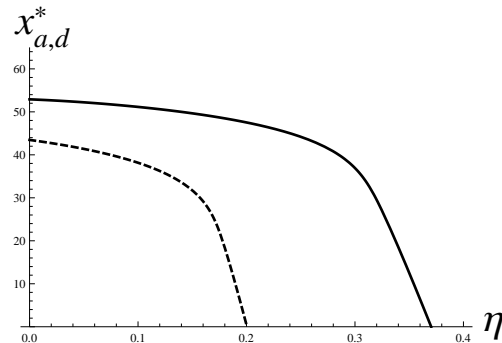

(b)

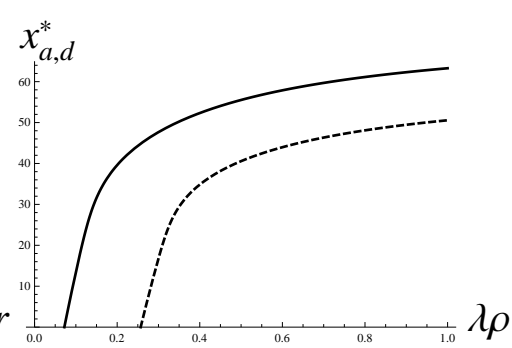

(e)

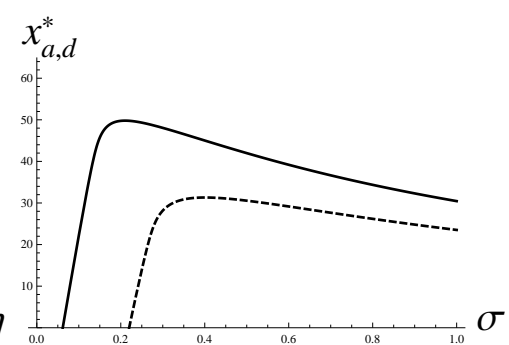

(c)

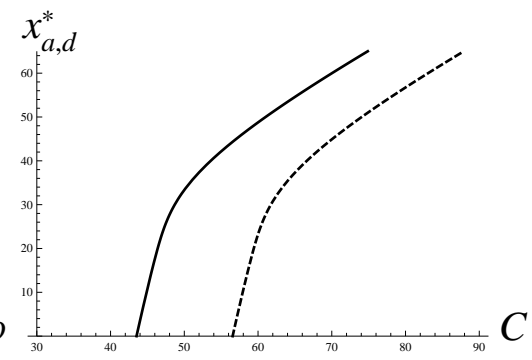

(f)

Figure 3: Default and abandonment threshold prices $x_{d}^{*}$ and $x_{a}^{*}$ as a function of (a) long-run mean price level $\bar{x}$, (b) speed of mean reversion $\eta$, (c) process volatility $\sigma$, (d) risk-free (real) interest rate $r$, (e) Sharpe ratio of oil $\lambda \rho$, (f) variable costs $C$, and (g) debt coupon payment $R$ (solid line $=x_{d}^{*}$, dashed line $=x_{a}^{*}$; for base-case parameters: $\bar{x}=\$ 97$, $\eta=0.1703, \sigma=0.265, r=0.04, \lambda \rho=0.32, C=\$ 60, R=\$ 13.50, \tau=0.3$ and $b=0.35)$. Note that these comparative statics are produced for fixed coupon $R$.

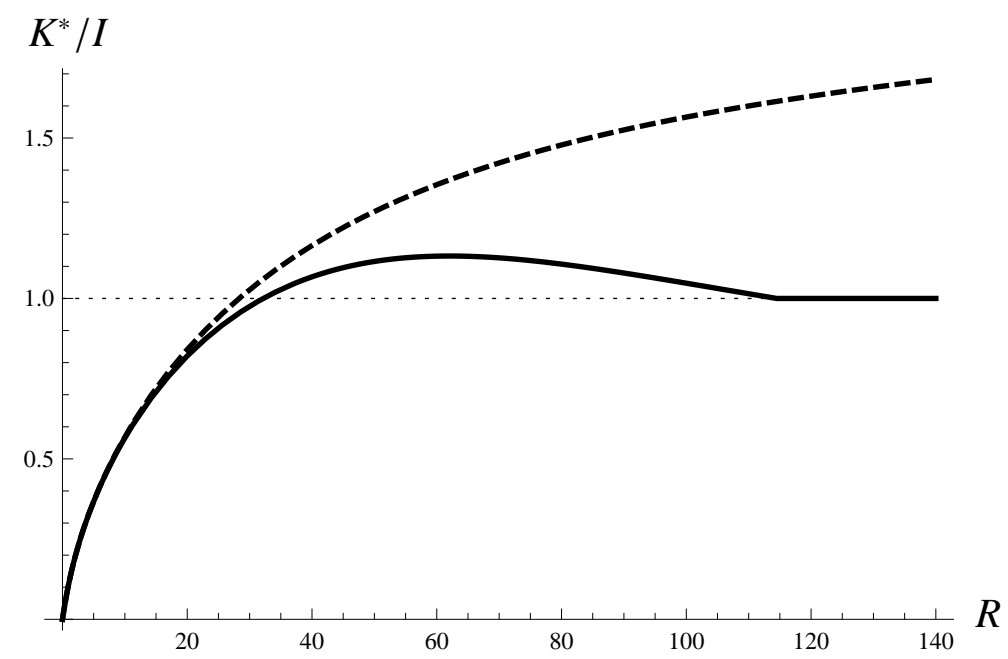

Figure 4: The equilibrium debt financing ratio $K^{*} / I$ as a function of the annual debt coupon payment $R$ (solid line $=$ second-best outcome, dashed line $=$ first-best outcome; for base-case parameters). Note the debtholders are very reluctant to give any debt over the required investment for the project (dotted line: $K^{*}=I$ ). 


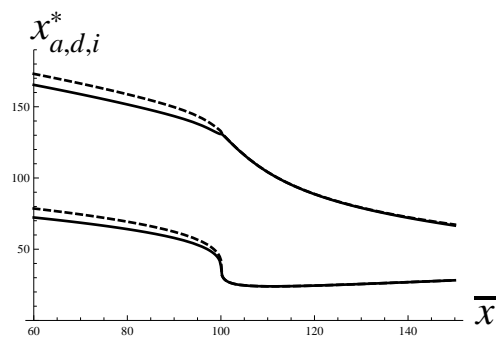

(a)

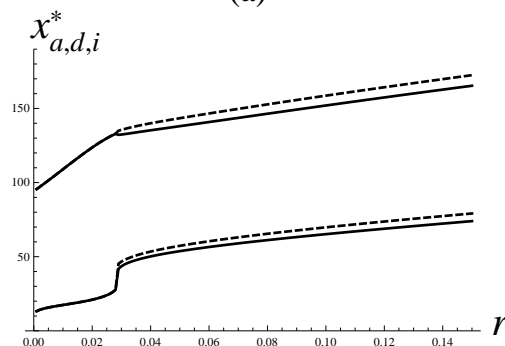

(d)

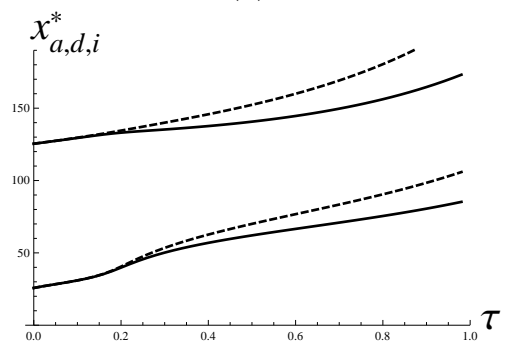

(g)

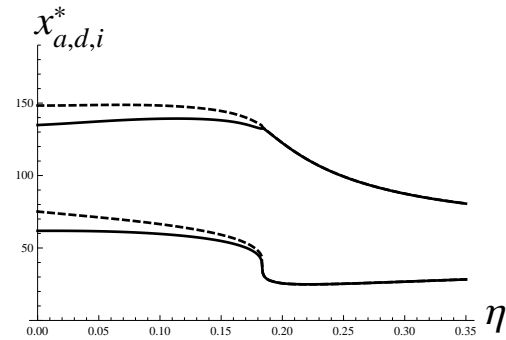

(b)

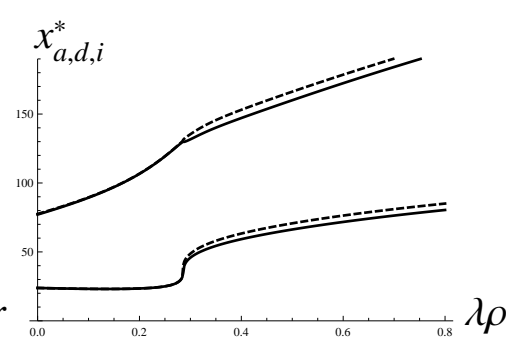

(e)

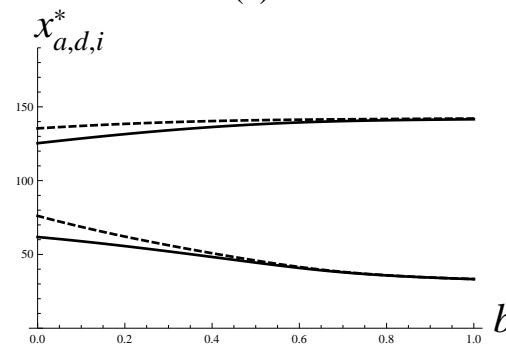

(h)

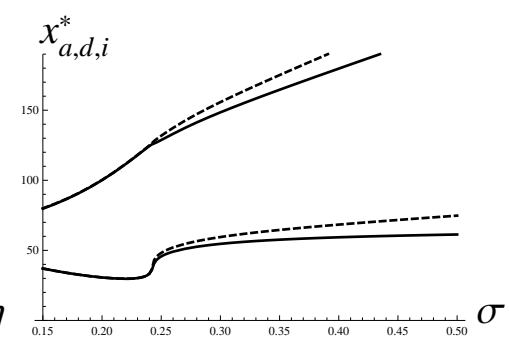

(c)

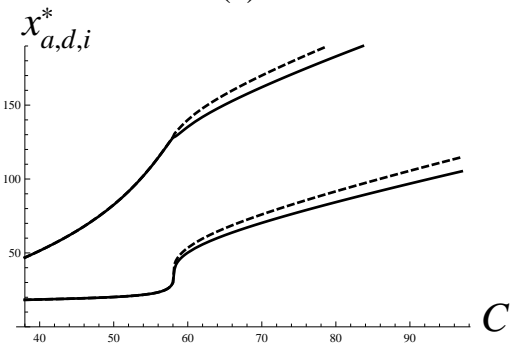

(f)

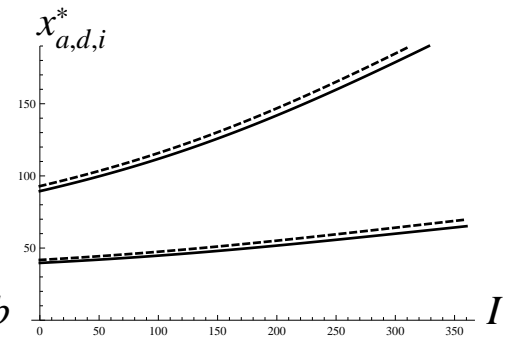

(i)

Figure 5: The first- and second-best investment threshold prices as a function of (a) long-run mean price level $\bar{x}$, (b) speed of mean reversion $\eta$, (c) process volatility $\sigma$, (d) risk-free (real) interest rate $r$, (e) Sharpe ratio of oil $\lambda \rho$, (f) variable costs $C$, (g) effective tax rate $\tau$, (h) bankruptcy fraction $b$, and finally (i) investment cost $I$ (upper solid line $=x_{2}^{*}$, upper dashed line $=x_{1}^{*}$, lower solid line $=x_{d}^{*}$, lower dashed line $=x_{a}^{*}$; for base-case parameters: $\bar{x}=\$ 97$, $\eta=0.1703, \sigma=0.265, \lambda \rho=0.32, r=0.04, \tau=0.3, b=0.35, C=\$ 60$ and $I=\$ 180)$. Note that the coupon rate $R$ is optimally chosen as each parameter is varied. 


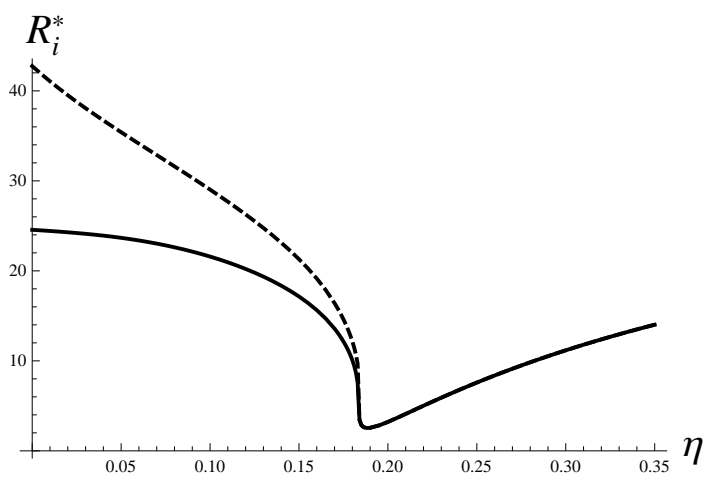

(a)

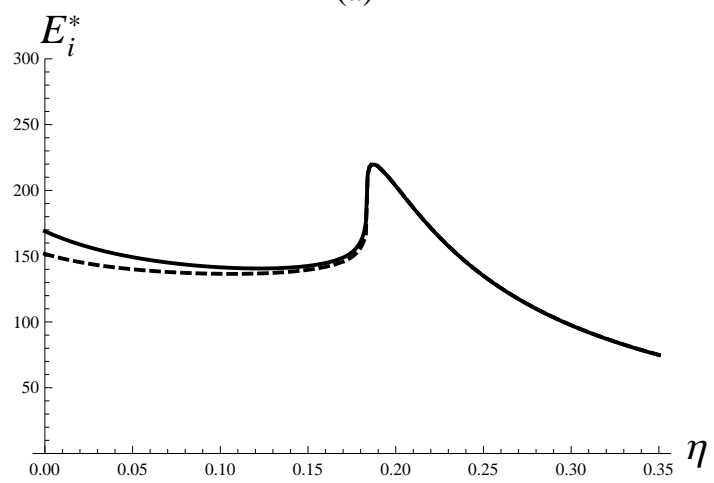

(c)

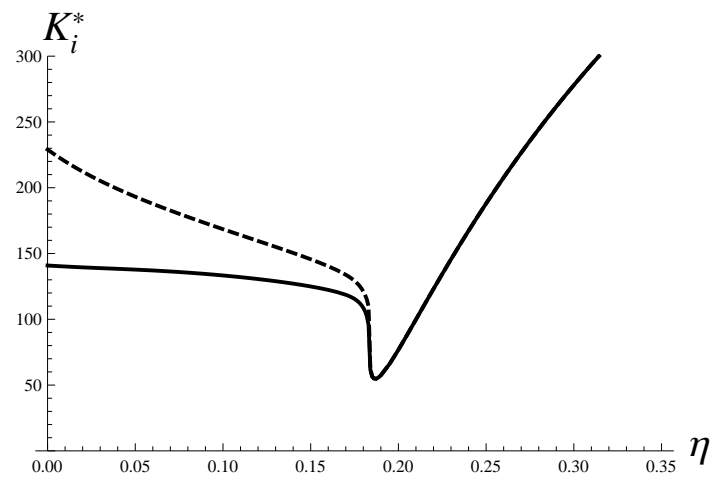

(b)

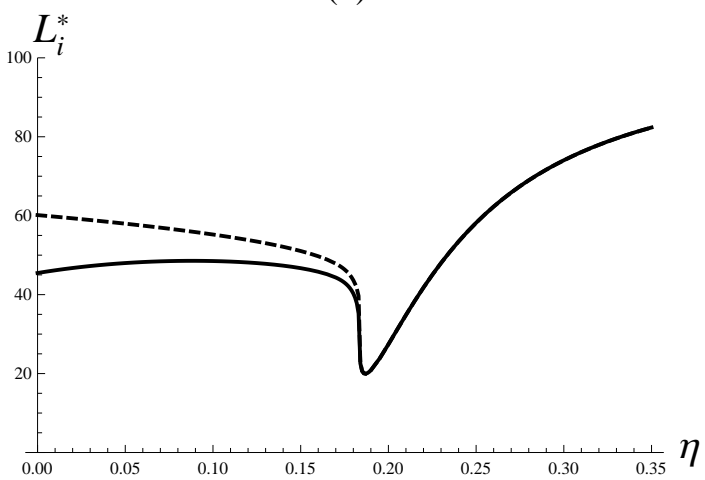

(d)

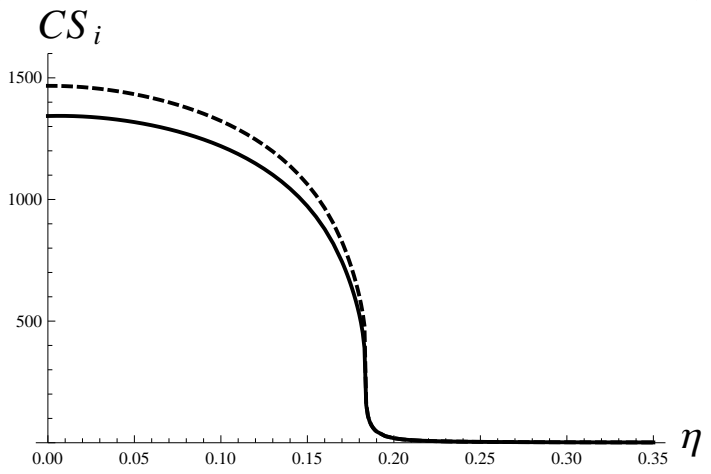

(e)

Figure 6: Full comparative statics (in equilibrium) with $\eta$ of the (a) coupon payment, (b) debt amount at time of investment, (c) equity value at time of investment, (d) leverage ratio at time of investment, and (e) credit spreads ( solid line $=$ second-best outcome, dashed line $=$ first-best outcome; for base-case parameters: $\bar{x}=\$ 97, \eta=0.1703$, $\sigma=0.265, r=0.04, \lambda \rho=0.32, C=\$ 60, \tau=0.3, b=0.35$ and $\left.X_{0}=\$ 100\right)$. 


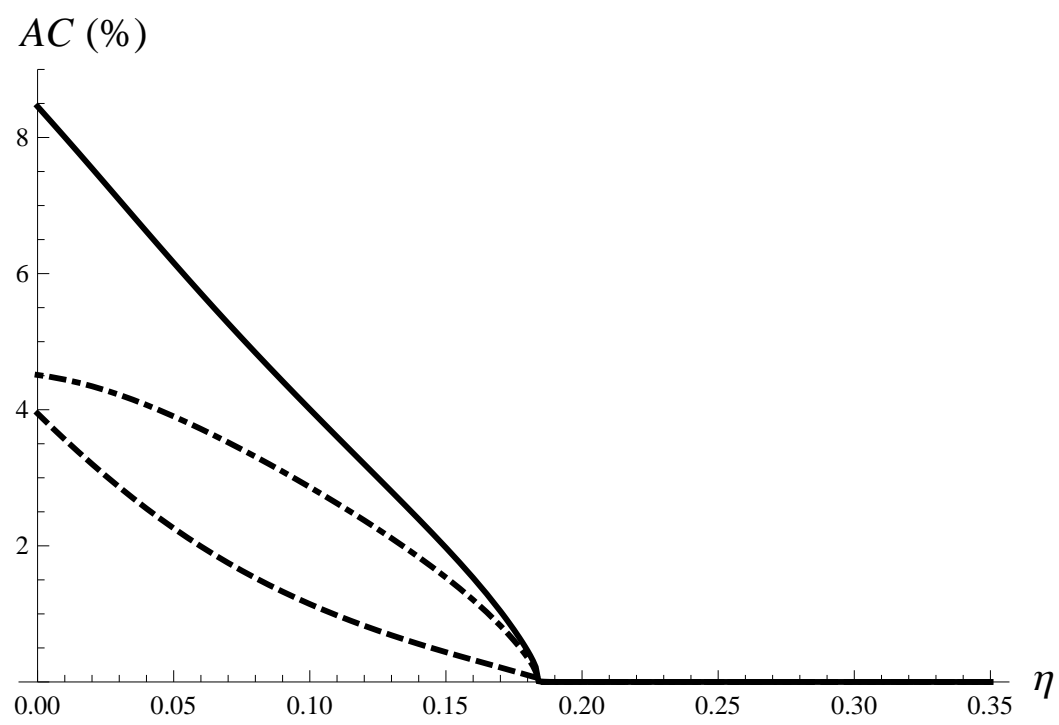

Figure 7: Full comparative statics (in equilibrium) of total agency cost (solid line) and its decomposition into $A C^{\text {fin }}$ (dashed line) and $A C^{\text {tim }}$ (dot-dashed line) — see Eq. (46)—under IGBM dynamics; for base-case parameters: $\bar{x}=\$ 97$, $\eta=0.1703, \sigma=0.265, r=0.04, \lambda \rho=0.32, C=\$ 60, \tau=0.3, b=0.35$ and $X_{0}=\$ 100$.

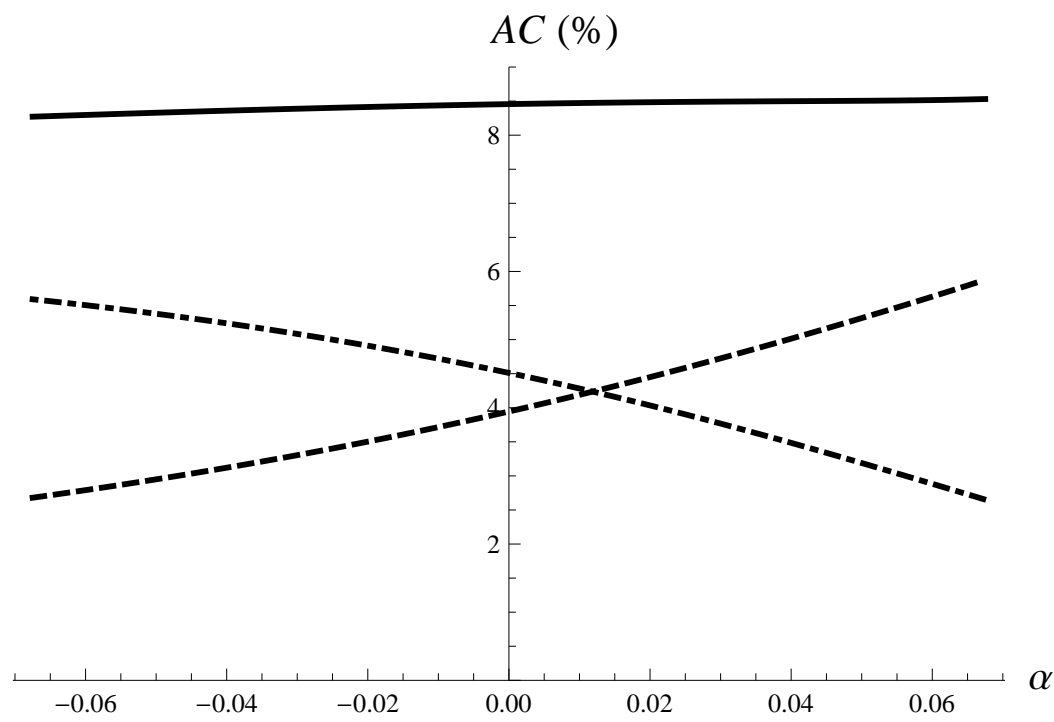

Figure 8: Full comparative statics (in equilibrium) of total agency cost (solid line) and its decomposition into $A C^{\text {fin }}$ (dashed line) and $A C^{t i m}$ (dot-dashed line)—see Eq. (46)—under GBM dynamics; for base-case parameters: $\bar{x}=\$ 0$, $\eta=-\alpha, \sigma=0.265, r=0.04, \lambda \rho=0.32, C=\$ 60, \tau=0.3, b=0.35$ and $X_{0}=\$ 100$. 
Table 1: Comparative statics of the first-best and second-best optimal financing and investment decisions in equilibrium; for base-case parameters: $\bar{x}=\$ 97$, $\eta=0.1703, \sigma=0.265, r=0.04, \lambda \rho=0.32, C=\$ 60, \tau=0.3, b=0.35$ and $X_{0}=\$ 100$.

\begin{tabular}{|c|c|c|c|c|c|c|c|c|c|c|c|c|c|}
\hline & \multicolumn{2}{|c|}{$\begin{array}{l}\text { Optimal } \\
\text { coupon }\end{array}$} & \multicolumn{2}{|c|}{$\begin{array}{l}\text { Investment } \\
\text { threshold }\end{array}$} & \multicolumn{2}{|c|}{ Firm value } & \multirow{2}{*}{$\begin{array}{c}\text { Agency } \\
\text { cost }(\%) \\
A C\end{array}$} & \multicolumn{2}{|c|}{$\begin{array}{l}\text { Optimal } \\
\text { leverage }\end{array}$} & \multicolumn{2}{|c|}{$\begin{array}{l}\text { Default } \\
\text { threshold }\end{array}$} & \multicolumn{2}{|c|}{$\begin{array}{l}\text { Credit spread } \\
\text { (basis points) }\end{array}$} \\
\hline & $R_{1}^{*}$ & $R_{2}^{*}$ & $x_{1}^{*}$ & $x_{2}^{*}$ & $F_{1}\left(X_{0}\right)$ & $F_{2}\left(X_{0}\right)$ & & $L_{1}^{*}$ & $L_{2}^{*}$ & $x_{d}^{*}\left(R_{1}^{*}\right)$ & $x_{d}^{*}\left(R_{2}^{*}\right)$ & $C S_{1}$ & $C S_{2}$ \\
\hline Base Case & 16.31 & 13.50 & 139.99 & 135.27 & 41.69 & 41.26 & 1.02 & 47.78 & 44.28 & 53.46 & 50.18 & 820.94 & 739.62 \\
\hline Base Case $(\eta=0)$ & 42.75 & 24.56 & 148.31 & 134.84 & 46.29 & 42.69 & 8.46 & 60.15 & 45.48 & 75.14 & 61.84 & $1,467.14$ & $1,343.09$ \\
\hline $\bar{x}=60$ & 34.98 & 28.00 & 173.10 & 165.37 & 3.05 & 2.89 & 5.59 & 56.28 & 50.88 & 78.59 & 72.27 & $2,150.55$ & $2,043.86$ \\
\hline $\bar{x}=80$ & 28.00 & 22.51 & 158.62 & 151.62 & 11.69 & 11.26 & 3.79 & 54.04 & 49.16 & 69.33 & 64.10 & $1,630.40$ & $1,530.44$ \\
\hline $\bar{x}=120$ & 12.81 & 12.81 & 88.78 & 88.63 & 313.07 & 313.07 & 0.00 & 68.19 & 68.24 & 24.46 & 24.46 & 2.82 & 2.82 \\
\hline $\bar{x}=140$ & 24.67 & 24.67 & 72.46 & 72.07 & 604.34 & 604.34 & 0.00 & 85.53 & 85.64 & 26.87 & 26.87 & 1.38 & 1.38 \\
\hline$\eta=0.10$ & 29.03 & 21.59 & 148.32 & 139.18 & 36.56 & 35.15 & 4.01 & 55.23 & 48.51 & 66.48 & 59.73 & $1,322.95$ & $1,219.24$ \\
\hline$\eta=0.15$ & 21.30 & 17.15 & 144.52 & 138.08 & 37.88 & 37.15 & 1.97 & 51.05 & 46.71 & 59.13 & 54.82 & $1,062.60$ & 972.59 \\
\hline$\eta=0.20$ & 3.21 & 3.21 & 122.54 & 122.45 & 66.01 & 66.01 & 0.00 & 27.40 & 27.41 & 25.61 & 25.61 & 18.59 & 18.58 \\
\hline$\eta=0.25$ & 7.59 & 7.59 & 99.37 & 99.31 & 216.12 & 216.12 & 0.00 & 58.19 & 58.21 & 25.32 & 25.32 & 3.62 & 3.62 \\
\hline$\sigma=0.20$ & 5.09 & 5.09 & 100.23 & 100.10 & 113.58 & 113.58 & 0.00 & 41.87 & 41.92 & 30.66 & 30.66 & 13.20 & 13.20 \\
\hline$\sigma=0.25$ & 11.61 & 9.78 & 131.77 & 128.73 & 47.49 & 47.27 & 0.46 & 43.67 & 40.61 & 48.18 & 45.68 & 560.09 & 494.46 \\
\hline$\sigma=0.30$ & 23.52 & 18.72 & 155.77 & 148.47 & 36.00 & 35.32 & 1.91 & 50.53 & 45.98 & 59.51 & 54.65 & $1,214.04$ & $1,105.92$ \\
\hline$\sigma=0.35$ & 31.70 & 24.09 & 175.06 & 164.59 & 34.44 & 33.55 & 2.66 & 51.96 & 46.23 & 64.58 & 57.63 & $1,608.70$ & $1,466.71$ \\
\hline$r=0.01$ & 3.01 & 3.01 & 108.98 & 108.97 & 337.84 & 337.84 & 0.00 & 55.62 & 55.63 & 17.44 & 17.44 & 0.46 & 0.46 \\
\hline$r=0.03$ & 11.18 & 8.90 & 135.58 & 132.40 & 60.00 & 59.76 & 0.00 & 42.78 & 38.77 & 46.69 & 43.56 & 583.71 & 498.97 \\
\hline$r=0.05$ & 19.46 & 16.18 & 143.42 & 138.05 & 31.22 & 30.77 & 1.49 & 50.02 & 46.46 & 57.35 & 53.75 & 942.61 & 858.33 \\
\hline$r=0.07$ & 24.32 & 20.35 & 149.71 & 143.63 & 19.34 & 18.93 & 2.18 & 52.84 & 49.23 & 63.07 & 58.98 & $1,086.55$ & 998.34 \\
\hline$\lambda \rho=0.20$ & 6.65 & 6.65 & 106.76 & 106.63 & 181.84 & 181.84 & 0.00 & 43.00 & 43.04 & 23.47 & 23.46 & 8.43 & 8.43 \\
\hline$\lambda \rho=0.30$ & 13.16 & 10.90 & 135.37 & 131.66 & 53.20 & 52.91 & 0.55 & 44.86 & 41.49 & 48.72 & 45.81 & 616.11 & 541.16 \\
\hline$\lambda \rho=0.40$ & 22.81 & 18.82 & 153.08 & 147.11 & 16.78 & 16.38 & 2.43 & 51.45 & 47.48 & 63.33 & 59.23 & $1,343.10$ & $1,250.79$ \\
\hline$\lambda \rho=0.50$ & 27.68 & 23.09 & 166.23 & 160.02 & 5.32 & 5.14 & 3.58 & 53.21 & 49.21 & 70.73 & 66.25 & $1,794.15$ & $1,698.02$ \\
\hline
\end{tabular}


Table 1: (continued).

\begin{tabular}{|c|c|c|c|c|c|c|c|c|c|c|c|c|c|}
\hline & \multicolumn{2}{|c|}{$\begin{array}{l}\text { Optimal } \\
\text { coupon }\end{array}$} & \multicolumn{2}{|c|}{$\begin{array}{l}\text { Investment } \\
\text { threshold }\end{array}$} & \multicolumn{2}{|c|}{ Firm value } & \multirow{2}{*}{$\begin{array}{c}\begin{array}{c}\text { Agency } \\
\text { cost }(\%)\end{array} \\
A C\end{array}$} & \multicolumn{2}{|c|}{$\begin{array}{l}\text { Optimal } \\
\text { leverage }\end{array}$} & \multicolumn{2}{|c|}{$\begin{array}{c}\text { Default } \\
\text { threshold }\end{array}$} & \multicolumn{2}{|c|}{$\begin{array}{l}\text { Credit spread } \\
\text { (basis points) }\end{array}$} \\
\hline & $R_{1}^{*}$ & $R_{2}^{*}$ & $x_{1}^{*}$ & $x_{2}^{*}$ & $F_{1}\left(X_{0}\right)$ & $F_{2}\left(X_{0}\right)$ & & $L_{1}^{*}$ & $L_{2}^{*}$ & $x_{d}^{*}\left(R_{1}^{*}\right)$ & $x_{d}^{*}\left(R_{2}^{*}\right)$ & $C S_{1}$ & $C S_{2}$ \\
\hline Base Case & 16.31 & 13.50 & 139.99 & 135.27 & 41.69 & 41.26 & 1.02 & 47.78 & 44.28 & 53.46 & 50.18 & 820.94 & 739.62 \\
\hline Base Case $(\eta=0)$ & 42.75 & 24.56 & 148.31 & 134.84 & 46.29 & 42.69 & 8.46 & 60.15 & 45.48 & 75.14 & 61.84 & $1,467.14$ & $1,343.09$ \\
\hline$\tau=0.10$ & 1.51 & 1.51 & 129.63 & 129.43 & 69.13 & 69.13 & 0.00 & 8.55 & 8.54 & 30.97 & 30.95 & 175.38 & 175.12 \\
\hline$\tau=0.20$ & 6.30 & 5.87 & 134.52 & 133.08 & 53.60 & 53.55 & 0.08 & 25.86 & 24.93 & 40.51 & 39.82 & 435.07 & 417.67 \\
\hline$\tau=0.40$ & 24.83 & 19.43 & 145.80 & 137.64 & 32.31 & 31.24 & 3.40 & 60.71 & 56.27 & 62.64 & 56.93 & $1,116.87$ & 979.51 \\
\hline$\tau=0.50$ & 32.16 & 24.28 & 152.33 & 140.68 & 24.54 & 22.77 & 7.76 & 69.45 & 64.97 & 70.05 & 62.08 & $1,375.38$ & $1,187.81$ \\
\hline$C=50$ & 8.92 & 8.92 & 82.63 & 82.54 & 226.93 & 226.93 & 0.00 & 60.46 & 60.50 & 20.17 & 20.17 & 3.53 & 3.53 \\
\hline$C=55$ & 4.31 & 4.31 & 108.12 & 108.04 & 106.10 & 106.10 & 0.00 & 34.53 & 34.55 & 22.37 & 22.37 & 11.65 & 11.65 \\
\hline$C=65$ & 23.76 & 19.18 & 157.13 & 150.27 & 25.07 & 24.49 & 2.40 & 51.81 & 47.38 & 66.66 & 61.98 & $1,274.95$ & $1,179.58$ \\
\hline$C=70$ & 28.28 & 22.44 & 170.06 & 162.12 & 17.10 & 16.56 & 3.33 & 53.57 & 48.50 & 76.03 & 70.33 & $1,548.47$ & $1,444.49$ \\
\hline$b=0.20$ & 24.32 & 18.25 & 138.45 & 131.51 & 45.06 & 43.96 & 2.50 & 60.89 & 54.77 & 62.12 & 55.64 & $1,008.56$ & 856.88 \\
\hline$b=0.30$ & 18.78 & 15.09 & 139.55 & 134.11 & 42.66 & 42.07 & 1.41 & 52.15 & 47.87 & 56.21 & 52.05 & 882.36 & 781.39 \\
\hline$b=0.40$ & 14.03 & 11.94 & 140.37 & 136.32 & 40.85 & 40.55 & 0.73 & 43.44 & 40.62 & 50.82 & 48.28 & 760.00 & 695.39 \\
\hline$b=0.50$ & 10.05 & 9.00 & 140.93 & 138.10 & 39.52 & 39.40 & 0.34 & 34.95 & 33.31 & 45.86 & 44.45 & 639.18 & 601.22 \\
\hline$I=100$ & 11.28 & 9.22 & 115.83 & 111.79 & 87.59 & 87.04 & 0.63 & 46.02 & 42.46 & 47.45 & 44.75 & 720.41 & 640.93 \\
\hline$I=140$ & 13.60 & 11.18 & 127.23 & 122.88 & 61.43 & 60.93 & 0.81 & 46.92 & 43.36 & 50.31 & 47.32 & 771.53 & 690.44 \\
\hline$I=220$ & 19.37 & 16.16 & 153.98 & 148.85 & 27.60 & 27.26 & 1.25 & 48.55 & 45.13 & 56.86 & 53.29 & 866.69 & 786.20 \\
\hline$I=260$ & 22.71 & 19.10 & 168.99 & 163.44 & 18.02 & 17.76 & 1.46 & 49.20 & 45.89 & 60.44 & 56.57 & 907.58 & 828.60 \\
\hline$\alpha=-0.06$ & 42.69 & 29.60 & 168.08 & 157.46 & 6.52 & 6.02 & 8.30 & 59.54 & 49.78 & 83.45 & 72.81 & $2,122.76$ & $1,998.24$ \\
\hline$\alpha=-0.03$ & 41.15 & 27.00 & 158.07 & 146.27 & 17.57 & 16.21 & 8.39 & 59.83 & 47.98 & 79.55 & 67.76 & $1,806.56$ & $1,681.07$ \\
\hline$\alpha=0.03$ & 46.00 & 22.66 & 139.37 & 123.30 & 122.33 & 112.75 & 8.49 & 60.52 & 42.05 & 70.03 & 54.61 & $1,103.79$ & 985.24 \\
\hline$\alpha=0.06$ & 56.62 & 22.58 & 132.65 & 111.88 & 343.03 & 316.11 & 8.51 & 61.03 & 37.77 & 64.08 & 45.37 & 728.42 & 620.83 \\
\hline
\end{tabular}


Table 2: Comparative statics of agency costs (in \%) and its timing and financing components; for base-case parameters: $\bar{x}=\$ 97, \eta=0.1703, \sigma=0.265, r=0.04, \lambda \rho=0.32, C=\$ 60, \tau=0.3, b=0.35$ and $X_{0}=\$ 100$.

\begin{tabular}{ll|ll}
\hline & $A C$ & $A C^{\text {fin }}$ & $A C^{\text {tim }}$ \\
\hline \hline Base Case & 1.02 & 0.21 & 0.81 \\
Base Case $(\eta=0)$ & 8.46 & 3.94 & 4.51 \\
\hline $\bar{x}=60$ & 5.59 & 1.23 & 4.37 \\
$\bar{x}=80$ & 3.79 & 0.82 & 2.97 \\
$\bar{x}=120$ & 0.00 & 0.00 & 0.00 \\
$\bar{x}=140$ & 0.00 & 0.00 & 0.00 \\
\hline$\eta=0.10$ & 4.01 & 1.14 & 2.86 \\
$\eta=0.15$ & 1.97 & 0.44 & 1.54 \\
$\eta=0.20$ & 0.00 & 0.00 & 0.00 \\
$\eta=0.25$ & 0.00 & 0.00 & 0.00 \\
\hline$\sigma=0.20$ & 0.00 & 0.00 & 0.00 \\
$\sigma=0.25$ & 0.46 & 0.09 & 0.36 \\
$\sigma=0.30$ & 1.91 & 0.44 & 1.47 \\
$\sigma=0.35$ & 2.66 & 0.70 & 1.96 \\
\hline$r=0.01$ & 0.00 & 0.00 & 0.00 \\
$r=0.03$ & 0.39 & 0.10 & 0.29 \\
$r=0.05$ & 1.49 & 0.30 & 1.19 \\
$r=0.07$ & 2.18 & 0.44 & 1.74 \\
\hline$\lambda \rho=0.2$ & 0.00 & 0.00 & 0.00 \\
$\lambda \rho=0.3$ & 0.55 & 0.12 & 0.43 \\
$\lambda \rho=0.4$ & 2.43 & 0.48 & 1.96 \\
$\lambda \rho=0.5$ & 3.58 & 0.65 & 2.93 \\
\hline
\end{tabular}

\begin{tabular}{ll|ll}
\hline & $A C$ & $A C^{\text {fin }}$ & $A C^{\text {tim }}$ \\
\hline \hline Base Case & 1.02 & 0.21 & 0.81 \\
Base Case $(\eta=0)$ & 8.46 & 3.94 & 4.51 \\
\hline$\tau=0.10$ & 0.00 & 0.00 & 0.00 \\
$\tau=0.20$ & 0.08 & 0.01 & 0.08 \\
$\tau=0.40$ & 3.40 & 0.85 & 2.55 \\
$\tau=0.50$ & 7.76 & 2.13 & 5.63 \\
\hline$C=50$ & 0.00 & 0.00 & 0.00 \\
$C=55$ & 0.00 & 0.00 & 0.00 \\
$C=65$ & 2.40 & 0.52 & 1.88 \\
$C=70$ & 3.33 & 0.76 & 2.57 \\
\hline$b=0.20$ & 2.50 & 0.73 & 1.77 \\
$b=0.30$ & 1.41 & 0.33 & 1.08 \\
$b=0.40$ & 0.73 & 0.13 & 0.60 \\
$b=0.50$ & 0.34 & 0.04 & 0.29 \\
\hline$I=100$ & 0.63 & 0.14 & 0.49 \\
$I=140$ & 0.81 & 0.17 & 0.64 \\
$I=220$ & 1.25 & 0.24 & 1.00 \\
$I=260$ & 1.46 & 0.27 & 1.19 \\
\hline \hline$\alpha=-0.06$ & 8.30 & 2.79 & 5.51 \\
$\alpha=-0.03$ & 8.39 & 3.30 & 5.08 \\
$\alpha=0.03$ & 8.49 & 4.72 & 3.77 \\
$\alpha=0.06$ & 8.51 & 5.63 & 2.88 \\
\hline & & & \\
\hline
\end{tabular}

